\title{
Attention-deficit-hyperactivity disorder and reward deficiency syndrome
}

\author{
Kenneth Blum 1,6,7,8,9,10 \\ Amanda Lih-Chuan Chen ${ }^{2}$ \\ Eric R Braverman 3,9 \\ David E Comings ${ }^{4}$ \\ Thomas JH Chen ${ }^{5}$ \\ Vanessa Arcuri ${ }^{9}$ \\ Seth H Blum 6 \\ Bernard W Downs 7,8 \\ Roger L Waite ${ }^{7}$ \\ Alison Notaro 9 \\ Joel Lubar ${ }^{10}$ \\ Lonna Williams ${ }^{7}$ \\ Thomas J Prihoda" \\ Tomas Palomo ${ }^{12}$ \\ Marlene Oscar-Berman ${ }^{13}$
}

'Department of Physiology and

Pharmacology, Wake Forest University

School of Medicine, Winston-Salem,

NC; ${ }^{2}$ Department of Engineering and

Management of Advanced Technology,

Chang Jung University, Tainan, Taiwan,

Republic of China; ${ }^{3}$ Department of

Neurosurgery, Weill College of

Medicine, New York, NY; ${ }^{4}$ Department of

Medical Genetics, City of Hope Medical

Center, Duarte, CA; ${ }^{5}$ Department

of Occupational Safety and Health,

Chang Jung University, Tainan, Taiwan,

Republic of China; ${ }^{6}$ Department of

Psychoneurogenetics, Synapatamine, Inc.

San Antonio, TX; ${ }^{7}$ LifeGen, Inc., La Jolla,

CA $;{ }^{8}$ Allied Nutraceutical Research,

Lederach, PA; ${ }^{9}$ PATH Research

Foundation, New York, NY; ${ }^{10}$ Department of Physiology, University of Tennessee,

Knoxville, TN; "'Department of

Pathology, University of Texas Health

Science Center, San Antonio, TX;

${ }^{12}$ Hospital Universitario 12 de Octubre,

Madrid, Spain; ${ }^{13}$ Boston University

School of Medicine, and Boston VA

Healthcare System, Boston, MA

Parts of this manuscript have been published in Theor Biol Med Model (Comings et al 2005), which is an open access journal

Correspondence: Marlene Oscar Berman Boston University School of Medicine and VA Healthcare System, 715 Albany Street, L-8I5, Boston, MA 02। I8, USA

Email oscar@bu.edu

Reprint requests: Kenneth Blum, Department of Physiology and Pharmacology, Wake

Forest University School of Medicine,

Winston-Salem, North Carolina

Email drd2gene@aol.com

\begin{abstract}
Molecular genetic studies have identified several genes that may mediate susceptibility to attention deficit hyperactivity disorder (ADHD). A consensus of the literature suggests that when there is a dysfunction in the "brain reward cascade," especially in the dopamine system, causing a low or hypo-dopaminergic trait, the brain may require dopamine for individuals to avoid unpleasant feelings. This high-risk genetic trait leads to multiple drugseeking behaviors, because the drugs activate release of dopamine, which can diminish abnormal cravings. Moreover, this genetic trait is due in part to a form of a gene ( $\mathrm{DRD}_{2} \mathrm{~A} 1$ allele) that prevents the expression of the normal laying down of dopamine receptors in brain reward sites. This gene, and others involved in neurophysiological processing of specific neurotransmitters, have been associated with deficient functions and predispose individuals to have a high risk for addictive, impulsive, and compulsive behavioral propensities. It has been proposed that genetic variants of dopaminergic genes and other "reward genes" are important common determinants of reward deficiency syndrome (RDS), which we hypothesize includes ADHD as a behavioral subtype. We further hypothesize that early diagnosis through genetic polymorphic identification in combination with DNA-based customized nutraceutical administration to young children may attenuate behavioral symptoms associated with ADHD. Moreover, it is concluded that dopamine and serotonin releasers might be useful therapeutic adjuncts for the treatment of other RDS behavioral subtypes, including addictions.
\end{abstract}

Keywords: attention deficit hyperactivity disorder (ADHD), genes, reward dependence, reward deficiency syndrome, treatment, neuropsychological deficits

\section{Characteristics of attention deficit hyperactivity disorder (ADHD)}

Attention deficit hyperactivity disorder (ADHD) is a complex disorder having multiple causes including genetics as impacted by one's environment. The condition is usually diagnosed in childhood, when difficulties arise during play and school, and it is marked by lack of concentration, short attention span, and physical restlessness (APA 1994; APA 2000). ADHD often is blamed on bad parenting, or a "bad" attitude. However, brain-imaging studies have shown that children with this disorder have an underlying neurological dysfunction, which likely accounts for their behavior (Zametkin et al 1990; Lou et al 1998). In the simplest terms, the brains of these children have yet to come fully "on-line." It is conjectured that while certain important brain pathways are working normally, cortical regions involved in attention, impulse control, and stimulus integration abilities, have yet to become fully active. ADHD is a widespread affliction that we are just beginning to understand. People with ADHD suffer from overload (Miller and Blum 2008). That is, they have heightened awareness of incoming stimuli, particularly sight, sound, and touch. They are so bombarded by the normal stimuli in their environment that they cannot filter out the background noise, and they have trouble focusing or concentrating on a problem or a task. Because of their inability to focus, those with ADHD have trouble completing what they start. They have difficulties 
with making plans and even more difficulty in carrying out plans in an orderly fashion.

People with ADHD tend to be disorganized. Children have messy rooms; adults have cluttered desks; daily activities tend to be chaotic. Attics and basements are likely to be filled with partly completed sewing projects, woodworking projects, repairs, and notebooks; desk drawers are likely to be cluttered with unfinished letters, outlines, and project plans. Many people with the disorder are highly intelligent, but they tend to be underachievers because they cannot concentrate or sustain interest. As a result, family, friends, teachers, and coworkers become impatient and expect them to fail. People with ADHD also have trouble adapting to change. Their life is so full of tumult that even a minor additional change in their routine can be upsetting or can even create a crisis, eg, a parent goes away on a trip, a new teacher takes over a class, the family moves to a new city, or a pet dies.

ADHD afflicted people live under stress so severe they cannot tolerate frustration, and when they are frustrated, they are likely to become angry. The anger tends to come suddenly and explosively, accompanied by slamming doors, harsh words, tantrums, and leaving important meetings in a frenzy. Children get into fights; adults lose jobs and alienate friends. Afterwards, they may be sorry, but the damage is done. With their high level of frustration, people with ADHD are impatient. They hate to wait in line, and delays of any kind can make them frantic. Whatever is going on - a trip, a movie, a class, a discussion - they want it to go quickly and be finished. Their impatience makes people with ADHD impulsive. As children, they leap into action without thinking of consequences. As adults, they drive too fast, use power tools carelessly, and plunge into activities without thinking of the danger. The result is they often hurt themselves or others. People with ADHD have trouble with their orientation to time and space. They may have trouble differentiating their right hand from their left; they may have difficulty following a set of instructions, reading a map, or telling time. As babies or children they constantly are on the move, squirming, twisting, and getting into everything. As adults, they are restless, easily bored, rebellious when asked to follow a routine, and always on the move. It is noteworthy that some of these characteristics are tied to comorbid Oppositional Defiant Disorder (ODD) and conduct disorder (CD), separate from ADHD per se (Biederman et al 2007b).

The diagnosis of ADHD is based on criteria outlined by the Diagnostic and Statistical Manual of the American Psychiatric Association (DSM-IV; APA 1994). Table 1 lists these criteria. There have been a number of similar criteria set out in earlier versions of the DSM. While the names have changed somewhat, all have embraced the letters ADD in one form or another, representing the core of the disorder - attention deficit disorder. The subtypes in the DMS-IV are ADHDI representing predominately the inattentive type, ADHD-H representing predominately the hyperactive-impulsive type, and ADHD-C, representing the combined type.

There has been increased interest in ADHD as a heritable neuropsychiatric condition linked to pathogenesis of brain dopamine (Shaw et al 2007; Swanson et al 2007; Volkow et al 2007). In the present paper, we discuss ADHD as an important putative complex subtype of a general condition or umbrella disorder known as reward deficiency syndrome (RDS) (Blum et al 1996a). RDS refers to the breakdown of a cascade of neurotransmitters in the brain in which one reaction triggers another - the reward cascade (Blum and Kozlowski 1990b) - and resultant aberrant conduct (Blum et al 1996a). At the level of individual neurons, the reward cascade is catalyzed by a number of specific neurotransmitters, each of which binds to certain types of receptors and serves a specific function. The binding of the neurotransmitter to neuronal receptors triggers a reaction that is part of the cascade. Disruption of these intercellular cascades results in aberrant behavior of one form or another in RDS, including ADHD.

RDS has genetic and environmental influences, and it predisposes individuals to high risk for multiple addictive, impulsive, and compulsive behaviors. Depending on genes that control different parts of the reward neurotransmitter pathways, a person may display anything from mild anxiety, irritability, hyperactivity, or risk taking, to compulsive shopping, gambling, sexual behaviors, drug addiction, alcoholism, smoking, and even eating disorders. Of all of these conditions, one that is especially controversial and receives considerable media coverage, is ADHD (APA 1994, 2000).

According to CHADD (Children and Adults with ADHD), 3.5 million school age children have ADHD (CHADD 2007). ADHD usually persists throughout a person's lifetime. It is not limited to children. Approximately one-half to two-thirds of children with ADHD will continue to have significant problems with ADHD symptoms and behaviors as adults, where it impacts their lives on the job, within the family, and in social relationships. ADHD is recognized as a disability under federal legislation (the Rehabilitation Act of 1973; the Americans with Disabilities Act; and the Individuals with Disabilities Education Act). Appropriate and reasonable accommodations are sometimes made at school for children with ADHD, and in the 
Table I DSM-IV diagnostic criteria for attention-deficit/hyperactivity disorder

A. Either (I) or (2)

(I) six (or more) of the following symptoms of inattention have persisted for at least 6 months to a degree that is maladaptive and inconsistent with developmental level:

Inattention

(a) often fails to give close attention to details or makes careless mistakes in schoolwork, work or other activities

(b) often has difficulty sustaining attention in tasks or play activities

(c) often does not seem to listen when spoken to directly

(d) often does not follow through on instructions and fails to finish schoolwork, chores, or duties in the workplace (not due to oppositional behavior or failure to understand instructions)

(e) often has difficulty organizing tasks and activities

(f) often avoids, dislikes, or is reluctant to engage in tasks that require sustained mental effort (such as schoolwork or homework)

(g) often loses things necessary for tasks or activities (eg, toys, school assignments, pencils, books, or tools)

(h) is often easily distracted by extraneous stimuli

(i) is often forgetful in daily activities

(2) six (or more) of the following symptoms of hyperactivity-impulsivity have persisted for at least 6 months to a degree that is maladaptive and inconsistent with developmental level:

Hyperactivity

(a) often fidgets with hands or feet or squirms in seat

(b) often leaves seat in classroom or in other situations in which remaining seated is expected

(c) often runs about or climbs excessively in a situation in which it is inappropriate (in adolescents or adults, may be limited to subjective feelings of restlessness)

(d) often has difficulty playing or engaging in leisure activities quietly

(e) is often "on the go" or often acts as if "driven by a motor"

(f) often talks excessively

Impulsivity

(g) often blurts out answers before questions have been completed

(h) often has difficulty awaiting turn

(i) often interrupts or intrudes on others (eg, butts into conversations or games)

B. Some hyperactivity-impulsive or inattentive symptoms that caused impairment were present before age 7 years

C. Some impairment from the symptoms is present in two or more settings (eg, at school [or work] and at home)

D. There must be clear evidence of clinically significant impairment in social, academic, or occupational functioning

E.The symptoms do not occur exclusively during the course of a Pervasive Developmental Disorder, Schizophrenia, or other Psychotic Disorder and are not better accounted for by other mental disorder (eg, Mood Disorder, Anxiety Disorder, Dissociative Disorder, or a Personality Disorder).

Code based on type:

3 1 4.0 I Attention-Deficit/Hyperactivity Disorder, Combined Type: if both Criteria AI and A2 are met for the past 6 months 3 14.00 Attention-Deficit/Hyperactivity Disorder, Predominately Inattentive Type: if Criteria Al is met but Criteria A2 is not met for the past 6 months

3 I 4.0 I Attention-Deficit/Hyperactivity Disorder, Predominately Hyperactive-Impulsive Type: if Criteria A2 is met but Criteria Al is not met for the past 6 months

workplace for adults with ADHD, which help the individual to work more efficiently and productively. While teachers are not equipped to make a definitive diagnosis, they are a meaningful source of initiation of the process to attain a sound diagnosis (Biederman et al 2006). However, less than half of those individuals who have been targeted by teachers receive appropriate diagnosis and corrective intervention. Of those who are diagnosed, few are receiving appropriate multi-modal treatment apart from pharmacological manipulation. Moreover, pediatricians report that approximately $4 \%$ of their patients have ADHD. Boys are four times more likely to have this illness than girls.
Twin studies indicate that $75 \%-90 \%$ of ADHD is caused by genetic factors. If one person in a family is diagnosed with ADHD there is a $25 \%-35 \%$ probability that another family member also has ADHD, compared to a $4 \%-6 \%$ probability for someone in the general population. Between $10 \%$ and $35 \%$ of children with ADHD have a first degree relative with past or present ADHD. Approximately one-half of parents who had ADHD have a child with the disorder. There may be non-genetic factors as well, including prenatal exposure to nicotine by mothers who smoked, anoxia in the neonatal period of infancy, and childhood exposure to high quantities of lead. 


\section{Science of reward deficiency syndrome}

RDS results from a dysfunction in the "brain reward cascade," a complex interaction among brain neurotransmitters in reward centers of the brain, which directly links abnormal craving behavior with a defect in at least the $\mathrm{DRD}_{2}$ dopamine receptor gene (Blum and Kozlowski 1990a). Dopamine is a powerful brain neurotransmitter that controls feelings of well being (Blum and Kozlowski 1990b; Blum and Payne 1991; Blum et al 1996a). Dopamine interacts with other powerful brain chemicals and neurotransmitters (eg, serotonin and the opioids), which themselves are associated with control of moods. In individuals possessing an abnormality in the $\mathrm{DRD}_{2}$ dopamine receptor gene, the brain lacks sufficient numbers of dopamine receptor sites to use the normal amount of dopamine in reward centers and thus reduces the amount of dopamine produced in this area. In individuals not possessing the variant in the dopamine receptor gene, but who have engaged in risky behaviors (such as cocaine abuse, extremely low caloric diet, high levels of stress over an extended period of time), the brain functions as though it had the $\mathrm{DRD}_{2}$ genetic variant (or other specific gene variants) (Faraone 2003). The overall effect is inadequate dopaminergic activity in brain reward centers. This defect drives individuals to engage in activities that will increase brain dopamine function. Consuming large quantities of alcohol or carbohydrates (carbohydrate bingeing) stimulates the brain's production of, and utilization of, dopamine. So too does the intake of crack/cocaine and the abuse of nicotine. Also, it has been found that the genetic abnormality is associated with aggressive behavior, which also stimulates the brain's use of dopamine (Blum et al 1996b, 2000).

RDS can be manifested in relatively mild or severe forms that follow as a consequence of an individual's biochemical inability to derive reward from ordinary, everyday activities. At least one genetic aberration has been identified that leads to an alteration in the reward pathways of the brain (Bowirrat and Oscar-Berman 2005). It is a variant form of the gene for the dopamine $\mathrm{D}_{2}$ receptor, called the $\mathrm{A} 1$ allele. This genetic variant also is associated with a spectrum of impulsive, compulsive, and addictive behaviors. The concept of the RDS unites those disorders and may explain how simple genetic anomalies give rise to complex aberrant behaviors. While this polymorphic gene may play a significant role in ADHD predisposition, it must be tied to a certain subset of additional genes for the clinical expression of ADHD. This is called polygenic inheritance. Recent associations of certain alleles of both the dopamine $\mathrm{D}_{4}$ and dopamine $\mathrm{D}_{2}$ genes and novelty seeking behavior have confirmed previous work suggesting polygenic inheritance (Comings et al 1996; Lee et al 2003).

\section{Biology of reward}

The reward system in the brain was discovered by accident in the 1950s by James Olds (Olds 1956). Olds had been studying brain mechanisms of attention using laboratory rats, when he mistakenly placed electrodes in a region of the limbic system. When the electrodes were attached so that the animals could self-stimulate this region by pressing a lever, rats would press the lever almost nonstop, as much as 5,000 times an hour. The animals would stimulate themselves to the exclusion of everything else except sleep. They also would endure tremendous pain and deprivation for an opportunity to press the lever. Olds had clearly found an area in the limbic system that provided a powerful reward for these animals.

Later research on human subjects revealed that the electrical stimulation of the medial hypothalamus in the limbic system produced a feeling of quasi-orgasmic sexual arousal. If certain other areas of the brain were stimulated, an individual experienced a type of light-headedness that banished negative thoughts (Olds 1956; Blum et al 2000). These discoveries demonstrated that pleasure is a distinct neurological function that is linked to a complex reward and reinforcement system. During the past several decades, research has been able to better define some of the brain regions and neurotransmitters involved in reward (Blum et al 1996a, 2000). A neuronal circuit deep in the brain involving the limbic system, the nucleus accumbens, and the globus pallidus, appears to be critical in the expression of reward (Wise and Bozarth 1984). Although each substance of abuse or each addictive behavior may act on different parts of this circuit, the end result is the same: Dopamine appears to be the primary neurotransmitter released in brain reward sites (Koob and Bloom 1988).

\section{Cascade theory of reward}

Considerable attention has been devoted to the investigation of the neurochemical and neuroanatomical systems that underlie a variety of substance-seeking behaviors. In healthy people, neurotransmitters work together in a pattern of stimulation or inhibition, the effects spreading downward, like a cascade, from stimulus input to complex patterns of response leading to feelings of well-being (cascade theory of reward; Stein and Belluzzi 1986; Blum and Kozlowski 1990b; Cloninger et al 1993). Although this neurotransmitter system is very complex and still not completely understood, the main 
central reward areas in the human brain's mesolimbic system are summarized below.

As can be seen in Figure 1, the following interactions take place in brain reward areas (Blum and Payne 1991; Stein and Belluzzi 1986): (1) Serotonin in the hypothalamus indirectly activates opiate receptors and causes a release of enkephalins in the ventral tegmental region $\mathrm{A}_{10}$. The enkephalins inhibit the firing of gamma-aminobutyric acid neurotransmitter (GABA), which originates in the substantia nigra $A_{9}$ region. (2) GABA's normal role, acting through GABA B receptors, is to inhibit and control the amount of dopamine released at the ventral tegmental regions for action at the nucleus accumbens. When dopamine is released in the nucleus accumbens, it activates dopamine $\mathrm{D}_{2}$ receptors. This release also is regulated by enkephalins acting through GABA. The supply of enkephalins is controlled by the amount of the neuropeptidases, which destroy them. (3) Dopamine also may be released into the amygdala. From the amygdala, dopamine exerts an effect on neurons within the hippocampus. (4) An alternate pathway involves norepinephrine in the locus ceruleus whose fibers project into the hippocampus at a reward area centering around cluster cells, which have not been precisely identified (designated as CAx). When GABA A receptors in the hippocampus are stimulated, they cause the release of norepinephrine.

It is to be noted that the putative glucose receptor in the hypothalamus is intricately involved and links the serotonergic system with opioid peptides leading to the ultimate release of dopamine at the nucleus accumbens. In the brain reward cascade these interactions may be viewed as activities of subsystems of a larger system, taking place simultaneously or in sequence, merging in cascade fashion toward anxiety, anger, low self-esteem, or other unpleasant feelings, or toward craving of a substance that will reduce or eliminate the feelings (eg, alcohol, carbohydrates, alcohol, and drugs) (Blum and Kozlowski 1990b).

The notion of dopamine as the final common pathway for a number of diverse drugs of abuse is supported by the findings of Ortiz and associates (Ortiz et al 1995). They demonstrated that chronic administration of cocaine, morphine, or alcohol resulted in several biochemical adaptations in the mesolimbic dopamine system. They suggested that these adaptations may underlie changes in the structural and functional properties of the neuronal pathway of this system related to substance abuse (Ollat et al 1990; also see Imperato and Di Chiara 1988).

Genetic anomalies, long-term continuing stress, or long-term abuse of substances can lead to a self-sustaining pattern of abnormal craving behavior in both animals and humans. Research on nonhuman animals has provided support for the cascade theory of reward and its genetic links. Thus, Li and colleagues (Russell et al 1988; Zhou et al 1991; McBride et al 1993, 1994; Li et al 2006) developed strains of alcohol-preferring (P) and non-preferring (NP) rat lines. They found that the $\mathrm{P}$ rats have the following neurochemical profile: lower serotonin neurons in the hypothalamus; higher levels of enkephalin in the hypothalamus (due to a lower release); more GABA neurons in the nucleus accumbens; reduced dopamine supply at the nucleus accumbens; and reduced densities of dopamine $\mathrm{D}_{2}$ receptors in the mesolimbic areas.

In terms of genetics, especially as related to ADHD, a number of genes have been associated, and these candidate genes are all involved in the reward cascade. Comings et al (2000) described a subset of at least 42 gene variants, which associate with ADHD and contribute to the overall variance. Interestingly, these genes constitute the basis for the reward cascade including certain neurotransmitters but not limited to dopaminergic, serotonergic, enkephalinergic, catecholaminergic, cholinergic, GABAergic, androgen receptors, as well as other putative transmitters, hormones, and their receptors and enzymes (both anabolic and catabolic).

In recent years, a number of reviews of the neurochemical basis of ADHD have emphasized the involvement of multiple neurotransmitters and emphasized that one single genetic defect cannot explain all of the data. Polygenic inheritance is uniquely capable of answering the question of how to account for both the range of comorbid disorders in ADHD and their interaction, but it fails to provide us with a true model of subsets of genes and their contribution to the variance of the disorder in question. One example of polygenic inheritance for ADHD was tested by Comings et al (2000). They found that three dopaminergic genes, $\mathrm{DRD}_{2}, \mathrm{DAT}_{1}$, and $\mathrm{DBH}$, differentially associated with ADHD probands. Their results showed that these three genes were additive in their effect. Thus, individuals who had three out of three markers had the highest ADHD score; those with two of three had the next highest score; then one of three; and those with none of the three markers had the lowest ADHD score (Comings et al 1996). Moreover, this additive effect was also seen for a number of other related ADHD behaviors (ie, stuttering, obsessive compulsive disorder [OCD], tics, conduct disorder [CD]) and supports the polygenic hypothesis of ADHD. In other words, the different associated behaviors are due to similar sets of genes in that certain psychiatric disorders have a number of genes in common. 


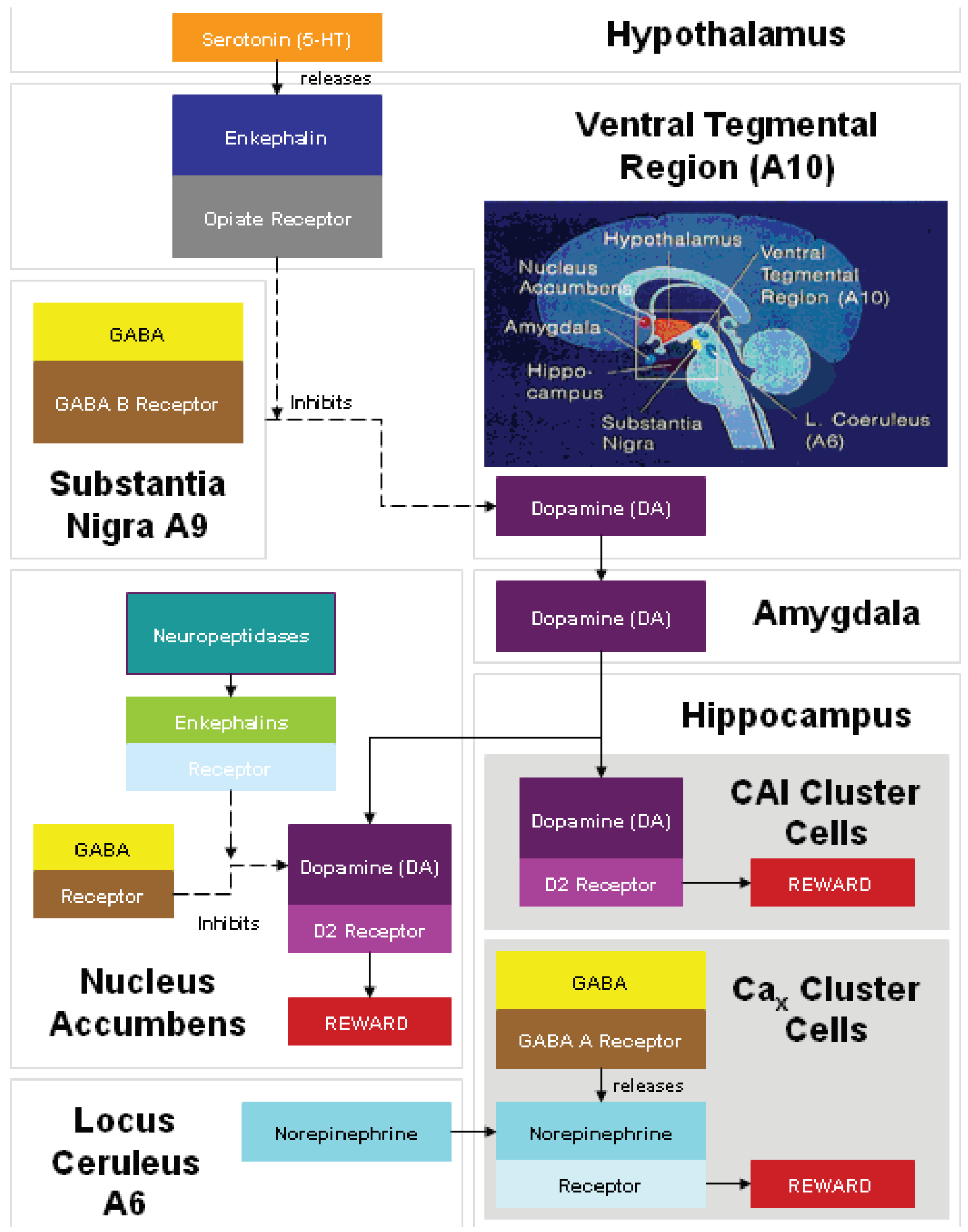

Figure I Interactions in brain reward regions. (I) Serotonin in the hypothalamus indirectly activates opiate receptors and causes a release of enkephalins in the ventral tegmental region $A_{10}$. The enkephalins inhibit the firing of GABA, which originates in the substantia nigra $A_{9}$ region. (2) GABA's normal role, acting through GABA $B$ receptors, is to inhibit and control the amount of dopamine released at the ventral tegmental regions for action at the nucleus accumbens. When dopamine is released in the nucleus accumbens, it activates dopamine $D_{2}$ receptors, a key reward site. This release is also regulated by enkephalins acting through GABA.The supply of enkephalins is controlled by the amount of the neuropeptidases that destroy them. (3) Dopamine also may be released into the amygdala. From the amygdala, dopamine stimulates the hippocampus and the $C A$ and cluster cells stimulate dopamine $D_{2}$ receptors. (4) An alternate pathway involves norepinephrine in the locus ceruleus whose fibers project into the hippocampus at a reward area centering around cluster cells that have not been precisely identified, but which have been designated as CAx. When GABA A receptors in the hippocampus are stimulated, they cause the release of norepinephrine. 
This suggests a four-part cascade sequence leading to a reduction of net dopamine release in a key reward area. Additional support for this idea came when investigators found that by administering substances that increase the serotonin supply at the synapse, or by stimulating dopamine $\mathrm{D}_{2}$ receptors directly, they could reduce craving for alcohol (McBride et al 1994). Specifically, $D_{2}$ receptor agonists reduced alcohol intake in high alcohol preferring rats, whereas $\mathrm{D}_{2}$ dopamine receptors antagonists increased alcohol drinking in these inbred animals (Dyr et al 1993).

\section{Science of ADHD \\ Neuropsychogenetics of ADHD}

In ADHD, the picture emerges of individuals suffering from overload, trying to adjust to a world that is too bright, too loud, too abrasive, and too rapidly changing for comfort. Early speculation about the causes of ADHD focused on such factors as marital disorder, poor parenting, brain damage, psychiatric illness, or alcoholism or drug abuse in the family. Associated behaviors included CD and anti-social personality. Later these behaviors were shown to be linked hereditarily to substance use disorder (SUD). Most recently, research has begun to show a significant association between these behavioral disorders, ADHD, and specific genetic anomalies.

What is the cause or basis of ADHD? It is an impulse disorder with genetic components that results from imbalances of neurotransmitters. Its effects can be eased by treatment and counseling. The biological basis for this disorder has been established by a number of investigators (Comings et al 1991; Biederman et al 1992). In one study individuals with ADHD were found to have abnormal brain wave patterns (Lubar 1991). Their beta waves (brain waves associated with concentration) are low, and their theta waves (associated with relaxation) are high, suggesting a state of drowsiness and daydreaming. It is not surprising, therefore, that activities associated with beta waves, eg, watchful anticipation and problem solving, are difficult for individuals with ADHD to sustain. They like activities that permit them to stay in a theta state with a minimum of outside stimulation (Lubar 1991). It may be that people with ADHD are afflicted with a defective filtering system such that their brainstem reticular formation does not block out irrelevant stimuli. These people appear to be aware of every sound, every object, every touch, and they all merge in disorganized behaviors that are difficult to tolerate. Non-essential stimuli get the same attention as those essential to work or relating to other people. At a deeper level, ADHD is a problem of communication among brain cells, or neurons, possibly involving the neurotransmitters that carry inter-neural messages. These brain messengers may be either in short supply for certain behaviors such as cravings (probably due to inadequate serotonergic and or dopaminergic function) or other attentional deficits, or they may be the result of too much norepinephrine rather than too little. If the messengers that inhibit incoming stimuli are deficient, too many signals get through and create confusion.

At a still deeper level, the problem lies in the genes that lay down the blueprint for manufacturing neurotransmitters. People with ADHD have at least one defective gene, the $\mathrm{DRD}_{2}$ gene that makes it difficult for neurons to respond to dopamine, the neurotransmitter that is involved in feelings of pleasure and the regulation of attention. Studies on genetic anomalies have implicated other dopaminergic genes such as the $\mathrm{DRD}_{4}$ receptor gene, the dopamine beta hydroxylase $(\mathrm{D} \beta \mathrm{H})$ gene, and the dopamine transporter genes as causative factors in ADHD (Cook et al 1995; Waldman et al 1996), as well as gene variants involved in multiple neurotransmitter pathways.

Support for the role of genetics in ADHD includes evidence showing that it runs in families. For example, a number of studies have shown that fathers and/or mothers of ADHD children tend to have antisocial personality and alcoholism. As early as 1971, James Morrison and Mark Stewart examined parents of 59 hyperactive children and 41 control children. In 21 of the families, at least 1 parent was alcoholic or had antisocial personality and other related behaviors. By contrast, only 4 of the control families were so affected. In a family study of parents and siblings of felons, there was an increased frequency of antisocial personality, alcoholism, and drug addiction in male relatives of hyperactive children (Cantwet al 1972).

Numerous studies indicate that $20 \%-30 \%$ of siblings of ADHD children also have ADHD. This is 2-7 times the frequency found in non-ADHD children. These siblings also were 5 times more likely to have major depression than control children (Welner et al 1977; August and Stewart 1983). Other studies showed that $22 \%$ of brothers and $8 \%$ of sisters of hyperactive children were hyperactive themselves. Interestingly, however, when ADD is considered without hyperactivity, the number of brothers and sisters affected was the same (Cantwell 1976). In another study of ADHD children it was found that if neither parent had the syndrome, $11 \%$ of the siblings had ADHD. If one parent had ADHD, 34\% of the siblings had ADHD (Pauls and Leckman 1986).

The observed fact that ADHD parents have an ADHD child does not prove that the problem is genetic. The question can be asked, was the behavior learned? One answer to the 
question is to look at siblings and half-siblings, both raised in the same environment. If ADHD is learned, the frequency should be the same for both. In actuality, half-siblings who have only half the genetic similarity show a significantly decreased frequency of ADHD (Safer 1973). In a study of twins, Willerman (1973), found that if one identical twin had ADHD, the other also had ADHD. If non-identical twins had ADHD, only $17 \%$ of the other twins had ADHD. This finding was confirmed in other independent studies.

Another approach is to look at the parents of ADHD children given up for adoption. If ADHD is a genetic disorder, the parents of children with the problem should show a higher frequency of ADHD, antisocial personality, or alcoholism than the adopting parents. In a study of ADHD children of ADHD parents who gave up their children at birth for adoption, it was found that the rate of antisocial personality, alcoholism, and ADHD was higher in the biological parents than in the adopting parents. In a study by Comings et al (1991), the investigators found that the $A_{1}$ allele of the dopamine $\mathrm{D}_{2}$ receptor gene was present in $49 \%$ of a sample of ADHD children compared to only $27 \%$ of controls. This was confirmed by Blum and associates (1993).

To some extent, people with ADHD can learn to cope. They can avoid situations that generate stress; avoid crowds and noisy environments; give themselves plenty of time and avoid tight deadlines; and avoid rapid changes in their environment. The most destructive coping strategy is selfmedication with alcohol or drugs. Such substances give the illusion that they are making life easier and more pleasant, for the symptoms seem to disappear. But the addiction quickly takes over, and life becomes a nightmare (Faraone et al 1991). Then, when they withdraw from alcohol or drugs, the ADHD problems return in full force.

The inherent tragedy here is that the ADHD person may be genetically at risk of developing an addiction. Possibly the same neurochemical imbalance in their brain that produces ADHD also produces a predisposition to addiction, Tourette syndrome, ODD, CD, and as well as other related behaviors (Comings et al 1991; Blum et al 1996b; Miller and Blum 2008).

\section{Behavioral and electrophysiological diagnostic tools}

In clinical settings, a number of rating scales have been utilized with mixed results for the diagnosis of ADHD. One set of commonly employed tools involves the Conners' Rating Scales (Conners 2006), an instrument that uses observer ratings and self-reports to help evaluate problem behaviors in children and adolescents. Another alternative utilized in a clinical setting to assist in properly diagnosing ADHD is a continuous performance test called T.O.V.A. (Test of Variables of Attention) (TOVA 2006). The latest version of this test is computerized, and it is designed to identify a minimum of four types of attention failures. One type is marked by omission abnormalities when the patient's attention failure is measured by missing information. The problem with relying on this parameter is that omission errors have been associated with a wide spectrum, including schizophrenia and petit mal seizure disorder, in which the attention failure is marked by neurological absences. The second type is marked by commission abnormalities associated with impulsive behaviors, and it frequently is co-morbid with a cluster of anxiety disorders (eg, obsessive compulsive behaviors, panic, and oppositional defiance). The third type is marked by abnormalities in reaction time. It is believed that this type is not specific for ADHD and is associated with slowing of response times as seen in classic psychomotor retardation, dysthymia, and major depression. The fourth type is response variability (either fast or slow). Of all the above, this is more closely related to ADHD and is also common in adults that have obesity, alcoholism, and/or craving disorders. It is this fourth type that is most likely linked to dopaminergic deficiency. However, it is important to note that results of T.O.V.A. tests have been associated with a number of false negative diagnoses.

To test the relationship between response variability and dopaminergic deficiency, we embarked on a study that examined associations between dopamine $\mathrm{D}_{2}$ receptor variants and T.O.V.A. scores (including response variability), as well as a measure of brain electrical activity, the P300 event related brain potential (Noble et al 1994). We studied 100 patients entering the PATH Medical Clinic, New York City, for a variety of medical complaints including neuropsychiatric, cardiovascular, and oncological problems. Each patient was given the T.O.V.A. and brain electrical activity mapping. When all the T.O.V.A. scores were summed $(<1$ standard deviation above the norm) a significant linear trend was observed, whereby increasing abnormal T.O.V.A. scores were associated with a percentage of patients having an abnormal prolonged P300 latency (normal being 300 plus age). Moreover, we found significant differences between the various scores (inattention, impulsivity, response time, and variability) and abnormal P300 latency (Braverman et al 2006). In contrast, only variability response was significant for P300 amplitude. This site-specific association may be attributable to dopaminergic variants. It is well known that 
the $\mathrm{DRD}_{2}$ gene $\mathrm{A} 1$ allele is associated with abnormalities in both the P300 latency and amplitude in well-screened alcoholics (Noble et al 1994). Thus, we must caution the clinician in terms of utilizing only one diagnostic tool to diagnose ADHD. We alternatively suggest that a number of tests including both Conners and T.O.V.A., as well as gene testing, be employed together.

\section{ADHD is a common disorder}

Estimates of the frequency of the various types of ADHD, based on population surveys, have shown variable results. A fairly common range is illustrated in Table 2 . The advantage of population based samples, in contrast to clinic based samples, is that individuals in the community who have not sought medical attention are included in the sample. In most locations, far fewer than $16 \%$, and usually less than $4 \%$, of the children in a given population receive treatment for a form of ADHD. This is contrary to the notion that the ADHD is overdiagnosed and overtreated. In fact, the majority of symptomatic children are not treated. Other associated disorders include CD and ODD.

While many of these children can be handled by appropriate teaching methods and do not require treatment, these figures suggest that ADHD-I at least, is probably under diagnosed and under treated. While the sex ratio for ADD-H and ADHD-C is 4:1, the sex ratio for ADD-I is closer to $1: 1$. This is a reflection of the fact that ADHD in girls tends to present as the inattentive type while boys are more likely to present as the hyperactive-impulsive or combined type. Symptoms of hyperactivity and impulsivity in school are obvious and disruptive, whereas symptoms of inattention are more subtle and non-disruptive; consequently, boys tend to be diagnosed and treated more than girls.

\section{ADHD is a spectrum disorder}

It has been known for many years that if an individual inherits enough genes to develop any given behavioral disorder, the risk of developing a second behavioral disorder is two to four times greater than for the general population. This is likely due to the fact that different behavioral disorders share some

Table 2 Prevalence of various types of ADHD in the general population

\begin{tabular}{ll}
\hline Hyperactive/Impulsive & 2.6 \\
Inattentive & 8.8 \\
Combined & 4.7 \\
Total & 16.1 \\
& M/F ratio 4:I \\
\hline
\end{tabular}

After Wolraich et al (1998). gene variants in common. Thus, the more a person exceeds the required threshold number of gene variants, the greater the likelihood of developing more than one behavioral problem, thus the term spectrum disorders. Some of the most common coexisting or comorbid spectrum disorders seen in individuals with ADHD are ODD, CD, major depressive disorder, anxiety disorders, OCD, bipolar disorder, learning disorders, and substance abuse disorder including alcoholism and drug addiction.

\section{ADHD has lifelong effects}

Having pointed out that much of the poor outcome in ADHD children is due to the comorbid presence of $\mathrm{CD}$, we would still like to present the studies of a 1985 report of Howell and coworkers (Howell et al 1985). While this longitudinal study did not distinguish between ADHD and ADHD plus $\mathrm{CD}$, it did something no other study has done. The study compared the outcome of three groups of children instead of just ADHD children and controls. Children in the early grade school years were evaluated on a continuum of ADHD symptoms and divided into three groups, those scoring in the highest 10\% (ADHD group) those in the lowest 10\% (low ADHD group) and the rest ("normal" group). They were then re-evaluated after they graduated from high school. The remarkable finding was that in virtually every aspect of their life the low ADHD group performed best, the normal individuals were intermediate and the ADHD group performed worst. This should not be taken to suggest that children with ADHD always underachieve. Again, we wish to emphasize there are many examples in which the restless, workaholic, always-have-to-be-doing-something, I-need-to-be-myown-boss, characteristics of ADHD subjects result in very successful lives. Thus, in the right combination, some of the symptoms we have been discussing in a negative light can be used to great advantage (Comings et al 2005).

\section{Genes and ADHD}

It has been proposed that ADHD is a polygenic disorder due to the additive effect of genes affecting dopamine, norepinephrine, serotonin, GABA, and other neurotransmitters (eg, see Comings et al 2000). Some of the specific loci involved are dopamine genes $\mathrm{DRD}_{1}, \mathrm{DRD}_{2}, \mathrm{DRD}_{4}, \mathrm{DRD}_{5}$, dopamine-beta-hydroxylase, and the dopamine transporter; norepinephrine and epinephrine genes ADRA2A, ADRA2C, PNMT, norepinephrine transporter, MAOA, catechol-Omethyltransferase (COMT); serotonin genes TDO2, HTR1A, HTR1DA, serotonin transporter; GABA genes GABRB3; androgen receptor and other genes. This model is consistent 
with present knowledge about ADHD including the following (Comings et al 2000): (a) the increased frequency of ADHD in the relatives of ADHD probands, (b) the presence of a wide spectrum of comorbid behaviors (depression, anxiety, learning, CD, ODD, and substance abuse disorders) in ADHD probands and their relatives on both parental sides, (c) the close relationship to Tourette syndrome, (d) the failure to find the genes for Tourette syndrome using linkage analysis, (e) the brain imaging studies showing hypometabolism of the frontal lobes, ( $f$ ) the relationship between dopamine $\mathrm{D}_{2}$ receptor density and regional blood flow, (g) the correlation between cerebral spinal fluid homovanilic acid levels and $\mathrm{DRD}_{2}$ genotypes, (h) the correlation between tics and dopamine $\mathrm{D}_{2}$ receptor density in Tourette syndrome, (i) the motor hyperactivity of dopamine transporter and dopamine $\mathrm{D}_{3}$ receptor gene knockout mice, (j) the Le Moal and Simon (1991) and Shaywitz et al (1976) dopamine deficiency animal models of ADHD, (k) the norepinephrine models of ADHD, (l) the failure to explain ADHD on the basis of any single neurotransmitter defect, $(\mathrm{m})$ the response of ADHD to dopamine and alpha-adrenergic agonists, (n) the small percentage of the variance of specific behaviors accounted for by each gene, and numerous other aspects of ADHD.

In one recent study (Brookes et al 2006), 1,038 singlenucleotide polymorphisms (SNPs) spanning 51 candidate genes involved in the regulation of neurotransmitter pathways, particularly dopamine, norepinephrine, and serotonin pathways, in addition to circadian rhythm genes, revealed interesting results. The analyses involved within-family tests of association in a sample of 776 DSM-IV ADHD combinedtype cases ascertained for an international multi-centre ADHD gene project. The researchers found nominal significance with one or more SNPs in 18 genes, including the two most replicated findings in the literature: $\mathrm{DRD}_{4}$ and $\mathrm{DAT}_{1}$. Gene-wide tests, adjusted for the number of single nucleotide polymorphisms (SNPs) analyzed in each gene, identified associations with the following: serotonergic (TPH2), adrenergic (ARRB2, ADRB2), dopaminergic (DAT 1 ), neurotransmitter metabolizing (MAO), pituitary development (HES1), enkephalinergic (PNMT), and synapase regulator (synaptophysin II [syp II]) gene polymorphisms.

\section{Molecular genetics and ADHD}

ADHD is not caused by poor parenting, family problems, poor teachers or schools, too much TV, food allergies or excess sugar. Instead, it is caused by biological and genetic factors that influence neurotransmitter activity in certain parts of the brain (Wallis et al 2008). Studies at the National Institute of
Mental Health using positron emission tomography (PET) scans to observe the brain at work have shown a link between a person's ability to pay continued attention and the level of activity in the brain. In people with ADHD, the brain areas that control attention used less glucose, indicating that they were less active. It appears from this research that a lower level of activity in some parts of the brain may cause inattention and other ADHD symptoms (Ernst et al 1988).

\section{A dopamine model}

Defects in dopamine metabolism have long been implicated in the etiology of ADHD. There are many reasons for this (Comings et al 1991; Kirley et al 2003): (1) LeMoal and Simon (1991) showed that lesions of the dopaminergic neurons of the ventral tegmental area resulted in hyperactivity, hyperresponsivity, poor response to stress, and a spectrum of other disorders. (2) Shaywitz and colleagues (1976) showed that chemical destruction of frontal lobe dopaminergic neurons shortly after birth produced an animal model of ADHD that responded to stimulants. (3) Catecholamines in the cerebral spinal fluid (CSF) of children with Tourette syndrome showed significantly lower levels of homovanillic acid (Leckman et al 1995). Some have also reported low CSF homovanillic acid in children with ADHD, while more recent studies have shown a positive correlation between CSF homovanillic acid and scores of hyperactivity and conduct disorder ADHD (Gerra et al 2007). (4) Brain imaging studies showed defects in the dopamine-rich striatum in ADHD (Krause et al 2003). (5) Furthermore, brain imaging studies indicate hypofunctionality of the frontal lobes in ADHD and Tourette syndrome. (6) Other studies have shown hyperactivity in knockout mice missing the dopamine transporter or $\mathrm{DRD}_{3}$ genes. (7) Further evidence demonstrated the effectiveness of dopaminergic agonists in the treatment of ADHD (la Fougere et al 2006). The following are some of the specific dopaminergic genes that have been implicated in the etiology of ADHD (see Figure 1).

\section{Dopamine $\mathrm{D}_{2}$ receptor gene $\left(\mathrm{DRD}_{2}\right)$}

The first molecular genetic studies of ADHD were reported in 1991 by Comings et al following the discovery by Blum and associates linking $\mathrm{DRD}_{2}$ A1 allele to severe alcoholism (Blum et al 1990). They examined the prevalence of the Taq A1 allele of the $\mathrm{DRD}_{2}$ gene in impulsive, compulsive, addictive behaviors. These results suggested that genetic variants at the $\mathrm{DRD}_{2}$ locus played a role in a range of impulsive, compulsive, addictive disorders, including ADHD. The prevalence of the $\mathrm{D}_{2} \mathrm{~A} 1$ allele in these disorders ranged from 42.3 to $54.5 \%$. While it was clear that the $\mathrm{DRD}_{2}$ was not a 
major gene causing these conditions, since it was usually not even present in half of the cases, it was also clear that the prevalence of the $\mathrm{D}_{2} \mathrm{~A} 1$ allele was approximately two-fold higher than in controls. An indication of the importance of the dopamine $\mathrm{D}_{2}$ receptor in Tourette syndrome comes from SPECT (single photon emission computed tomography) studies of monozygotic twins discordant for tic severity. For example, differences in $\mathrm{D}_{2}$ receptor density in the head of the caudate nucleus predicted differences in phenotypic severity with the almost unheard of correlation coefficient of $\mathrm{r}=0.99, \mathrm{p}<0.001$, suggesting that striatal dopamine $\mathrm{D}_{2}$ receptor density accounted for $98 \%$ of the variance of tic severity (Wolf et al 1996).

In a subsequent study of individuals who smoked at least one pack of cigarettes per day and were unable to quit on their own, it was found that $48 \%$ carried the Taq I $\mathrm{D}_{2} \mathrm{~A} 1$ allele (Comings et al 1996a) and had trouble sleeping (Vandenbergh et al 2007). The prevalence Taq I D A1 allele was even higher in a large group of pathological gamblers (Comings et al 1996b). It was also verified in post-traumatic stress disorder (Lawford et al 2006). The initial interpretation was that the $\mathrm{DRD}_{2}$ gene modified the effect of an unidentified major gene for Tourette syndrome and ADHD. The important feature is that the $\mathrm{DRD}_{2}$ gene accounted for less than $5 \%$ of the variance of a number of quantitative traits relating to ADHD and other behaviors. As the number of genes showing a similar modest effect were identified (see below), and as the failure to find any gene causing a major effect continued, we and others began to favor the polygenic mode of inheritance for ADHD, Tourette syndrome, and other psychiatric disorders (Noble 2003). Moreover, recent work indicates that other RDS related behaviors including adolescent excessive internet video gaming are significantly associated with the $\mathrm{DRD}_{2} \mathrm{~A} 1$ allele (Han et al 2007). Interestingly, in both Borderline Personality Disorder as well as healthy individuals, the presence of the $\mathrm{DRD}_{2} \mathrm{~A} 1$ allele correlated with the commission of more time violations on a test sensitive to the integrity of the frontal lobes, and especially in the healthy subjects, with longer execution times. This work suggests that the $\mathrm{DRD}_{2}$ gene could exert an effect on executive functioning controlled by frontal brain systems.

\section{Dopamine $\mathrm{D}_{2}$ receptors, regional blood flow, and response to methylphenidate}

In reviews of published articles that examined striatal dopamine transporter (DAT) density in ADHD patients, Krause et al $(2003 ; 2006)$ cited numerous neuroimaging findings of elevation in that region. Additionally, Krause et al (2005) investigated whether availability of striatal DAT may have an influence on the response of adult ADHD patients to methylphenidate, as measured with SPECT scans. They found that ADHD individuals with low DAT availability failed to respond to methylphenenidate therapy. Also using SPECT technology, Volkow and colleagues $(1995,1997)$ examined the relationship between the effects of methylphenidate on regional blood flow and the density of dopamine $\mathrm{D}_{2}$ receptors in various regions of the brain. In some subjects, methylphenidate increased regional blood flow while in others it decreased blood flow. The changes in the frontal, temporal and cerebellar metabolism were related to the density of $\mathrm{D}_{2}$ receptors - the higher the density the greater the increases in blood flow. Methylphenidate decreased the relative metabolic activity of the basal ganglia. These results are consistent, indicating that genetic defects in dopamine metabolism, resulting in a hypodopaminergic state in the limbic system and frontal lobes, result in a compensatory increase in dopaminergic activity in the basal ganglia, and that methylphenidate reverses these through a combination of enhancing brain dopamine activity by inhibition of the dopamine transporter, with a secondary decrease in dopaminergic activity in the basal ganglia and a decrease in basal ganglia blood flow. These studies are also consistent with the results of Castellanos and colleagues (1998) showing a positive correlation between the response to methylphenidate and CSF levels of homovanillic acid, a metabolite of dopamine whose levels in the CSF are related to $\mathrm{D}_{2}$ receptor density.

One of the intriguing aspects of the Volkow et al (1995) study was the finding that methylphenidate consistently increased cerebellar metabolism, despite the paucity of $\mathrm{D}_{2}$ receptors in this structure. This is consistent with the increasing evidence that the cerebellum plays an important role in attention, learning, and memory.

In support of the above studies, Noble et al (1997) also found an association between the Taq $\mathrm{I} \mathrm{D}_{2} \mathrm{~A} 1$ genotype and regional blood flow. Using PET and ${ }^{18} \mathrm{~F}$-deoxyglucose, they observed that A1 carriers showed a significantly lower relative glucose metabolism in the putamen, nucleus accumbens, frontal and temporal gyri and medial prefrontal, occipito-temporal and orbital cortices than those with the A22 genotype. Noble and Blum and associates had previously shown that Taq $\mathrm{I} \mathrm{D}_{2} \mathrm{~A} 1$ carriers had a significantly decreased dopamine $\mathrm{D}_{2}$ receptor in the basal ganglia. In a different PET study, Farde et al (1997) observed a significant decrease in dopamine $\mathrm{D}_{2}$ receptor density in individuals with detachment, social isolation, and lack of intimate friendships. 


\section{Heterosis at the $\mathrm{DRD}_{2}$ gene}

Within the past decade, Comings et al have examined the role of the $\mathrm{DRD}_{2}$ gene in a range of behaviors, and have noticed a persistent tendency for quantitative behavioral scores to be highest in 12 heterozygotes, lowest in 11 homozygotes, and intermediate in 22 homozygotes. Most often the relationship is $12>>22>11$ or $12>>11=22$. The presence of a greater effect in heterozygotes than either homozygote is termed heterosis. Strong support for heterosis at the $\mathrm{DRD}_{2}$ gene comes from research by Jönsson et al (1996). They compared the CSF levels of the dopamine breakdown product homovanillic acid to the $\mathrm{DRD}_{2}$ genotype using the Taq $\mathrm{I}_{2} \mathrm{~A} 1$ polymorphism. There was a remarkable similarity to the profile for the inattention score in the Tourette syndrome subjects, with 12 heterozygotes showing the highest inattention score, and the Jönsson et al (1996) subjects who were 12 heterozygotes had the lowest levels of CSF homovanillic acid. The highest levels of homovanillic acid were seen in the 11 homozygotes, with the levels in 22 homozygotes being intermediate. This suggests that subjects with the lowest levels of CSF homovanillic acid had the most symptoms of ADHD. While this is consistent with some studies showing a significantly lower level of CSF homovanillic acid in children with ADHD and Tourette syndrome, it seems to conflict with the studies of Castellanos et al (1998) showing a positive correlation among some aspects of symptom severity and response to methylphenidate, and CSF homovanillic acid levels. However, these studies only examined children with ADHD and did not include controls. While it is yet to be studied, those individuals carrying the Taq $\mathrm{I}_{2} \mathrm{~A} 1$ allele may not be those who respond best to methylphenidate.

Recent PET and SPECT studies of the relationship between the Taq I genotypes of the $\mathrm{DRD}_{2}$ gene and number of dopamine $\mathrm{D}_{2}$ receptors in the striatum, support the effect of molecular heterosis producing the lowest level of $\mathrm{D}_{2}$ receptors in 12 heterozygotes, the highest levels in 11 homozygotes and high levels in 22 homozygotes. These combined results provide the first illustration of a direct connection between a genotype, a neurotransmitter level (dopamine), and ADHD symptoms. While the studies of homovanillic acid levels in ADHD have been variable, these results suggest that some ADHD is associated with low CSF levels of homovanillic acid and this in turn is related to heterozygosity for the $\mathrm{DRD}_{2}$ Taq I alleles. In contrast, Noble et al (1994) found that the lowest level of $\mathrm{D}_{2}$ density was found in the 11 homozygote.

In an attempt to further our understanding of the role of genes in ADHD as a subtype behavior of RDS, we embarked on a research study involving generational family-based subjects genotyped for three dopaminergic genes.

\section{Dopamine transporter gene}

The dopamine transporter is responsible for moving dopamine across the presynaptic membrane back into the nerve cell from which it was released. In a recent review of the literature (Comings et al 2005), the $\mathrm{DAT}_{1}$ gene was considered an important candidate gene for ADHD, because it is a major dopaminergic gene, and it is the site of action of methylphenidate and dexedrine, widely used in the treatment of ADHD. These stimulant medications inhibit the transport process, resulting in an increase in synaptic dopamine. Cook et al (1995) reported a significant positive association between the 10 allele of the $\mathrm{DAT}_{1}$ gene and 49 cases of ADHD using the haplotype relative risk procedure. When eight cases of undifferentiated ADD were added, the results were unchanged. Using the family based haplotype relative risk procedure, Gill et al (1997) also found a significant preferential transmission of the 10 allele in 40 parent-child sets.

Comings (2001) also observed a significant association between the 10 allele and ADHD and a range of other behavioral variables in Tourette syndrome probands. For example, in a group of 352 Tourette syndrome probands and control subjects, the mean cumulative ADHD score based on counts of DSM-III ADHD criteria, was 25.44 for those that were $10 / 10$ homozygotes versus 20.42 for those that were not $10 / 10$ homozygotes. Consistent with these results, Malison et al (1995), using SPECT imaging, reported a significant increase in the level of dopamine transporter protein in the striatum of Tourette syndrome subjects compared to controls.

Knockout mice missing the $\mathrm{DAT}_{1}$ genes are very hyperactive. While these mice show increased motor activity in open field studies, they were dramatically more hyperactive in smaller spaces. This suggests that the stress of being confined contributes to the hyperactivity. This is analogous to the contribution of the $\mathrm{DRD}_{2}$ gene to both hyperactivity and poor response to stress in humans. Studies of the DAT knockout mice showed a five-fold increase in brain dopamine levels, down-regulation of $\mathrm{D}_{2}$ receptors, uncoupling of $\mathrm{D}_{2}$ receptor function, and a $57 \%$ decrease in body size. While the presence of hyperactivity in the absence of $\mathrm{DAT}_{1}$ genes may seem to conflict with the above results, suggesting hyperactivity in the presence of increased activity of the human $\mathrm{DAT}_{1}$ gene, the presence of compensatory and plastic changes in other dopaminergic systems occurring when major defects of the dopamine transporter are present from conception, may account for the differences. 
Alternatively, because of complex inhibitory and stimulatory loops, both increases and decreases (too much or too little) in the amount of receptor or transport protein may result in similar symptoms. In contrast to the above results, LaHoste et al (1996) did not find a significant increase in the frequency of the DAT 10 allele in their group of ADHD subjects. They showed, instead, an increase in the prevalence of the 7 allele of the $\mathrm{DRD}_{4}$ gene.

Waldman et al (1998) have also examined the role of the $\mathrm{DAT}_{1}$ gene in ADHD. In their first report, they used the transmission disequilibrium technique (a family-based association test to examine the linkage between a genetic marker and a trait) to determine the role of the $\mathrm{DAT}_{1}$ gene in ADHD, ODD and CD in 123 families. They found a significant association between the $\mathrm{DAT}_{1} 10$ allele and ODD, CD, and hyperactivity-impulsivity. After controlling for the level of hyperactivity-impulsivity symptoms, the association with ODD and CD was no longer significant, suggesting that the relationship between childhood ODD and CD was mediated through its effect on hyperactivity and impulsivity. In a subsequent report, they examined 74 ADHD probands, 79 siblings, and a control sample of 49 twins. The mean scores for hyperactivity/impulsivity, inattentiveness, ODD, CD, and depression and dysthymia were progressively lower across these three groups. The inclusion of parents allowed family based association studies. It was of interest that the greatest power came from discordant siblings. Twelve of the 41 siblings were discordant for the high risk $\mathrm{DAT}_{1}$ alleles (10 repeat), and in 10 of these, the siblings carrying the high risk alleles had significantly higher scores for hyperactive-impulsive symptoms and for inattentive symptoms. The transmission disequilibrium test also showed association and linkage of the 10 repeat with the combined form of ADHD. Of the 10 studied, eight were positive for a role of the $\mathrm{DAT}_{1}$ gene in ADHD. Winsberg and Comings (1999) examined the correlation between response to methylphenidate treatment and $\mathrm{DAT}_{1}$ genotype in a series of 30 African-American children with ADHD. Of the responders, only $31 \%$ carried the $10 / 10$ genotype while $86 \%$ of the non-responders carried the $10 / 10$ genotype, suggesting that in this population 10/10 homozygosity is associated with a poor response to stimulant treatment. Although these interesting pharmacogenomic findings have been confirmed by some (Kirley et al 2003), they await further replication.

A recent meta-analysis concluded that there is a significant association between ADHD and dopamine system genes, such as $\mathrm{DAT}_{1}$, but even more robust with regard to the $\mathrm{DRD}_{4}$ and $\mathrm{DRD}_{5}$ genes (Li et al 2006). Of further interest, Mill et al (2006) presented evidence that polymorphisms in the $\mathrm{DRD}_{4}$ and $\mathrm{DAT}_{1}$ genes were associated with variation (compromise) in intellectual functioning among children diagnosed as having ADHD. The same authors further showed from longitudinal evidence that these polymorphisms predicted which children with ADHD were at greatest risk for poor adult prognosis (also see Heiser et al 2004; Madras et al 2005; Larsson et al 2006).

\section{Generational association studies of dopaminergic genes in RDS probands and family members}

At this point, it is important to emphasize that polymorphisms of the dopamine $\mathrm{D}_{2}$ receptor gene are associated with RDS and number of related impulsive, addictive, and compulsive behaviors. In an unpublished study with Joel Lubar from the University of Tennessee, Knoxville, and Judith Lubar at the Southwestern Biofeedback and Neurobehavioral Clinic, the authors genotyped 51 subjects from four generations derived from two multiply-affected families All subjects were genotyped for three of the dopaminergic genes $\left(\mathrm{DRD}_{2}\right.$, $\mathrm{DAT}_{1}$, and DBH). In this study $80 \%$ of all subjects (40 of $50)$ carried the $\mathrm{DRD}_{2}$ Taq $1 \mathrm{~A} 1$ allele. When compared with "highly screened controls called super controls" (1/30 or $3.3 \%$ of the controls carried the $\mathrm{DRD}_{2} \mathrm{~A} 1$ allele), a highly significant association was observed. It is noteworthy that as the number of RDS behaviors increased in the subjects, the prevalence of the $\mathrm{DRD}_{2} \mathrm{~A} 1$ allele also increased. This work allows one to utilize genotyping to access certain personality factors such as ADHD and other related RDS behaviors.

\section{The role of polygenes as a diagnostic indicator}

While there is much evidence for the involvement of the dopaminergic system and specific genes involved and treatment possibilities, other models including genes related to dopamine $\mathrm{D}_{4}$, dopamine $\mathrm{D}_{5}$, dopa decarboxylase gene, norepinephrine, adrenergic ${ }_{2 \mathrm{a}}$ and ${ }_{2 \mathrm{c}}$, COMT, tryptophan 2,3dioxygenase, and GABA should also be considered (see a review by Comings (2001)).

In terms of polygenic inheritance, Hawi et al (2005) observed that several genes are associated with ADHD, including $\mathrm{DAT}_{1}, \mathrm{DBH}_{1} \mathrm{DRD}_{4}, \mathrm{DRD}_{5}$ and $5 \mathrm{HT} 1 \mathrm{~B}$. Moreover, linkage studies using affected sibling pairs and extended pedigrees have identified several chromosomal regions containing putative ADHD susceptibility genes. Chromosomal regions highlighted by replication across studies are 
accumulating evidence with increasing sample size and include chromosomes 5p13, 6q12, 16p13, and 17p11 (ArcosBurgos et al 2004; Asherson et al 2005).

Kent et al (2005) found evidence to support the hypothesis that the gene BDNF (brain-derived neurotrophic factor) located at $11 \mathrm{p} 13$ and encoding for a precursor peptide (proBDNF), is associated with ADHD. Additionally, Turic and others (2005a) found evidence that genes related to glutamate function such as SLC1A3 (Solute Carrier Family 1 , member 3 ) in a family based study may contribute to susceptibility to ADHD. Other genes that have been associated with ADHD susceptibility include the calcyon gene (DRD11p) (Laurin et al 2005); beta hydroxylase gene (Inkster et al 2004) NR4A2 gene (Smith et al 2005) and the COMT gene (Turic et al 2005b).

Understanding the genetic meaning of carrying the $\mathrm{DRD}_{2}$ and $\mathrm{DAT}_{1}$ polymorphisms to assist in the diagnosis of ADHD is of paramount importance. One must first consider the difference between a single-gene-single-cause concept as in the situation with Cystic Fibrosis or Huntington's disease, or even Muscular Dystrophy, compared to multiple genes involved in complex disorders such as ADHD (Comings et al 1996). With regard to psychiatric genetic anomalies such as schizophrenia, bipolar disorder, Alzheimer disease, RDS, among other related behaviors, dopaminergic allelic presence does not necessarily diagnose the disorder. On the other hand if an individual carries one or more of these associated polymorphisms, the scientific evidence supports a diagnosis of predisposition and high probability that the subject is at greater risk for having the disorder in question or may at some time in the future present with typical clinical symptoms. Moreover, we do know from the use of Bayes theory to predict outcomes, that carriers born with the dopamine $\mathrm{D}_{2}$ receptor $\mathrm{A} 1$ allele have a $74 \%$ chance that they would have RDS behavior (Blum et al 1990, 1996b).

This predisposition diagnosis is typical in that the same parameters and limitations that have been placed on other diseases such as so called oncogenes for cancer, as well as the gene for diabetes, are the same for RDS. There is a tendency in psychiatric genetics to think in terms of the singlegene-single-disorder model and to lose sight of the fact that polygenic inheritance has its own distinct set of rules. There are some distinct issues that are relevant to the genetics of ADHD. A major point is that polygenic inheritance is far more complex than single gene inheritance. The ultimate truth about the role of any one gene involved in polygenic inheritance may require a summation across many different studies and the examination of the additive genes involved in both childhood and adult ADHD and their comorbid disorders. Once the gene map of ADHD is uncovered, it will provide improved diagnosis (prevent over-diagnosis) and treatment (non-drug, non-addictive, efficacious and safe) of these very common disorders and demonstrate for all but the most recalcitrant critic that these are real biological entities.

Comings (2001) summarized the role of multiple genes in ADHD providing a polygenic model for the etiology of ADHD including the following salient points modified herein:

- Multiple dopaminergic genes and other genes each contributing to a small percentage of the total variance.

- The co-morbidity between ADHD and substance abuse (common sets of genes affecting the frontal lobes and the reward pathways).

- The central role of the frontal lobes and ADHD and related disorders.

- The evidence from animals that defects of dopamine metabolism in the frontal lobes are important in ADHD.

- The secondary hypersensitivity of dopamine receptors in the basal ganglia leading to hyperactivity and tics.

- The close relationship between ADHD and Tourette syndrome.

- The role of norepinephrine genes in learning and language disorders involving parietal lobe attention centers.

- The role of serotonergic and GABAergic genes in the reward cascade.

- The role of enkephalinergic genes as they relate to dopamine release.

\section{Treatments for ADHD}

The website for the American Academy of Child and Adolescent Psychiatry (AACP) states, "The goal of any type of ADHD treatment is to reduce symptoms and help the child function at a normal level. Treatment may include medication, therapy, family support, educational support, or a combination of these" (http://www.aacap.org/cs/adhd_a_ guide_for_families/getting_treatment).

Symptoms of ADHD often are treated with drugs, an approach that conforms to mainstream medical and regulatory guidelines. Common conventional therapies are targeted at suppressing symptoms by inhibiting, blocking, or (conversely) amplifying production, reception and/or disposal of various neurotransmitters (eg, serotonin with selective serotonin reuptake inhibitors). These therapies carry some associated undesirable risks. When pharmacological agents are administered to children, reactions often are polarized. Some critics object to the prospect of millions of children who are 
prescribed controlled substances that are potentially addictive and injurious to the brain. Others support the opportunity given to people diagnosed with ADHD (including adults) for receiving the clinical attention they deserve, including effective treatment, despite side effects. Whatever treatment option is chosen, in order to provide an effective outcome for individuals with ADHD, it is important to recognize the following: First, individuals may be born with a predisposition to behavioral symptoms associated with ADHD and other RDS disorders. Second, these various RDS disorders involve complex interactions of neurotransmitters. Third, ADHD may be the precursor for multiple addictions including alcohol, drugs, food, sex, and even gambling. And fourth, there is an association between a severe form of alcoholism and defects in the $\mathrm{D}_{2}$ gene in the reward area of the brain and other dopaminergic genes (ie, the dopamine transporter gene and the dopamine betahydroxylase gene) (Blum et al 1996a; Pohjalainen et al 1998; Bowirrat and Oscar-Berman 2005). While the genetics are far more complex than these genes, carriers of dopaminergic gene variants, or genetic deficits including these or other gene subsets, can develop behavioral manifestations of RDS.

\section{Pharmacological treatments}

\section{Stimulants}

Pharmacological treatment with psychostimulants is the most widely studied treatment for ADHD. Stimulant treatment has been used for childhood behavioral disorders since 1933. While stimulant treatments are highly effective for $75 \%-90 \%$ of children with ADHD, at least four separate psychostimulant medications consistently reduce the core features of ADHD in literally hundreds of randomized controlled trials: methylphenidate, dextroamphetamine, pemoline, and a mixture of amphetamine salts.

These medications are metabolized, leave the body fairly quickly, and work for up to four hours. (Widely prescribed drugs, Concerta and Adderall, are believed to last 6-12 hours.) These medications have their greatest effects on symptoms of hyperactivity, impulsivity, and inattention, and the associated features of defiance, aggression, and oppositionality. They also improve classroom performance and behavior, promoting increased interaction with teachers, parents and peers.

Many double blind studies over the past 40 years have uniformly agreed that stimulants such as methylphenidate, dextro-amphetamine, as well as other substances, are very effective in the treatment of $70 \%-80 \%$ of children and adults with ADHD. One of the myths of ADHD is that ADHD children show a paradoxical effect of being calmed by stimulants, while "normal" individuals are stimulated by them. However, studies have shown that the activity levels are decreased and attention levels are increased by stimulants in individuals with and without ADHD. The difference is that since the levels of hyperactivity and inattention are much higher in ADHD subjects, the improvement is relatively much greater, giving the impression that they respond, while non-ADHD subjects do not.

It is known that like the effect of serotonin re-uptake inhibitors on the serotonin transporters, stimulants inhibit both dopamine transporters and norepinephrine transporters. Since hyperactivity is related to excessive dopamine activity in the basal ganglia, on the surface this would seem to make things worse instead of better. However, Figure 2 shows how the stimulants work in ADHD. This results in a decrease in dopaminergic stimulation in the basal ganglia where the density of the $\mathrm{D}_{2}$ receptors is the highest. Of particular interest, there are few $\mathrm{D}_{2}$ receptors in the prefrontal lobe. Thus, dopamine activity in the prefrontal lobes is increased instead of decreased. This is consistent with a model of ADHD in which there is too little dopamine in the frontal lobes, resulting in symptoms of prefrontal lobe deficits and too much dopamine in the basal ganglia, such as motor hyperactivity and not infrequently, motor tics. The stimulants correct both the prefrontal lobe deficiency of dopamine and the basal ganglion excess of dopamine.

Despite this indication of how uniquely suited stimulant medications are to the treatment of ADHD, they can have undesirable side effects such as insomnia, decreased appetite, stomachaches, headaches, and jitteriness. Some children may develop tics. Other side effects include rebound hyperactivity and psychosis. Pemoline has been associated with hepatotoxicity, so monitoring of liver function is necessary. Additionally, many still worry that ADHD children are receiving a form of "speed". Studies have shown that in order to obtain a "high", stimulants need to reach the brain very quickly. This requires intravenous or nasal administration, or the use of doses that exceed therapeutic recommendations. At therapeutic oral doses, the stimulants used for treatment of ADHD do not cause a euphoric high. Perhaps the best indicator of this is that one of the hardest parts of the treatment for ADHD children is to get them to take their medication. This, however, is no guarantee that these drugs are never abused. It is important that children and adolescents with ADHD not have free access to their medications, since it is clear that these drugs can be abused when given nasally, or intravenously, or in high doses. Keeping track of the medications helps to ensure that they are not sold for illicit use.

In addition to the use of stimulant medications, a second class of medications that works primarily on norepinephrine 




Figure 2 Diagrammatic representation of the mechanisms of action of stimulants in treating ADHD. Figure 2a (top left) shows the basal unstimulated state with dopamine stored in the vesicles and low levels of dopamine in the synapse. Figure $2 b$ (top right) shows the result of stimulation of the dopamine neuron with the vesicles releasing dopamine into the synapse and re-uptake of dopamine into the presynaptic neuron by the dopamine transporters. Figure $2 \mathrm{c}$ (bottom left) shows that in the presence of stimulants, the function of the dopamine transporters is partially blocked and the basal level of dopamine increases in the synapse. This results in the occupation of the presynaptic dopamine $D_{2}$ receptors by dopamine. Now, when the nerve is stimulated (Figure $2 d$, bottom right), because of the occupation of the presynaptic $D_{2}$ receptors, the amount of dopamine released from the vesicles is decreased. Adapted from Seeman and Madras (1998).

pathways (eg, clonidine, guanifacine, and atomoxetine, can also be quite effective (Perwien et al 2006; Spencer et al 2001, 2006). Clonidine and guanifacine are especially useful in treating individuals with both ADHD and chronic tics (Tourette syndrome) since clonidine and guanifacine uniquely treat both ADHD and Tourette syndrome. Physicians are often reluctant to treat individuals with both ADHD and Tourette syndrome with stimulants, for fear of exacerbating the tics. However, consistent with the above mechanism of action of stimulants, significant exacerbation is unusual, and often the tics are unchanged or improve following stimulant treatment (Gadow et al 1992).

As alluded to above, it is often the comorbid disorders such as ODD and CD that cause the greatest distress to parents of children with ADHD. In our experience, the atypical neuroleptics such as risperidone, olanzipine, and molindone, can be very effective in the treatment of these comorbid conditions.

\section{Other medications}

For children with ADHD who do not respond to stimulants $(10 \%-30 \%)$ or cannot tolerate the side effects, other alternatives may be available. However, other competitive solutions also have been tried with mixed results (Friel 2007). The anti-depressant bupropion has been found to be superior to placebo, although the response is not as strong as stimulants. Well-controlled trials have shown tricyclic antidepressants to be superior to placebo but less effective than stimulants. 
Reports of sudden death of a few children in the early 1990s on the tricyclic compound desipramine led to great caution with the use of tricyclics in children.

Clonidine can be an effective mode of treatment of ADHD. Since it also treats motor and vocal tics, it is especially useful in the treatment of Tourette-syndrome children who also have ADHD. Neuroleptics have been found to be occasionally effective, yet the risk of movement disorders, such as tardive dyskinesia, makes their use problematic. Lithium, fenfluramine, or benzodiazepines have not been found to be effective treatments for ADHD, nor have serotonin re-uptake inhibitors such as fluoxetine.

Another drug being tested is lisdexamfetamine dimesylate (LDX), a therapeutically inactive prodrug in which d-amphetamine is covalently bound to 1-lysine, a naturally occurring amino acid. Pharmacologically active d-amphetamine is released from LDX following oral ingestion. A phase 2, randomized, double-blind, placeboand active-controlled crossover study compared the efficacy and safety of $\operatorname{LDX}(30,50$, or $70 \mathrm{mg})$ with placebo, with mixed amphetamine salts (extended-release 10, 20, or 30 $\mathrm{mg}$ ) included as a reference arm of the study, in 52 ADHD children aged 6-12 years in an analog classroom setting (Biederman et al 2007a). The primary efficacy measure was the Swanson, Kotkin, Agler, M-Flynn, and Pelham (SKAMP) Rating Scale. Secondary efficacy measures included the Permanent Product Measure of Performance (PERMP) Derived Measures, and the Clinical Global Impression (CGI) Scale. Results showed that LDX treatment significantly improved scores on SKAMP-deportment, SKAMP-attention, PERMP-attempted, PERMP-correct, and CGI-improvement from baseline. Adverse events were similar for both active treatments. In a laboratory classroom environment, LDX significantly improved ADHD symptoms versus placebo in school-age children with ADHD.

\section{Overprescription of stimulants}

Concerns have been raised that children, particularly active boys, are being overdiagnosed with ADHD and thus are receiving psychostimulants unnecessarily. While recent reports suggest that overprescription and overdiagnosis are unfounded, a more important issue is that fewer children ( $2 \%-3 \%$ of school-aged children) are being treated for ADHD than suffer from it (Farone 2003). Treatment rates are lower for selected groups such as girls, minorities, and children receiving care through public service systems. However, there have been major increases in the number of stimulant prescriptions since 1989, and methylphenidate is being manufactured at 2.5 times the rate of a decade ago (Comings et al 2005). Nonetheless, some of the increase in use may reflect inappropriate diagnosis and treatment. In one study, the rate of stimulant use was twice the rate of parent-reported ADHD, based on standardized psychiatric interview (Comings et al 2005). Moreover, in 2005, 4.4\% of children (ages $0-19$ ) and $0.8 \%$ of adults (ages 20 and older) used ADHD medications. During the period between 2000 and 2005, treatment prevalence increased rapidly (11.8\% per year; Castle et al 2007). In addition, global use of ADHD medications rose threefold from 1993 to 2003, whereas global spending (US\$2.4 billion in 2003) rose 9-fold, adjusting for inflation (Scheffler et al 2007).

While a number of stimulant drugs are utilized to treat ADHD symptoms, a promising alternative approach involves a natural polypharmacy directed at correction and control of neurochemistry and dopamine $\mathrm{D}_{2}$ receptor proliferation, while minimizing side effects (Blum et al 2006a). It also involves a noninvasive DNA based diagnostic test for the determination of predisposing sets of polymorphic genes and their interaction (known as epistasis). However, this treatment approach also can be accomplished in combination with known FDA-approved stimulants.

\section{The polypharmacy and multigenetic approach}

The polygenic inheritance of ADHD and its comorbid disorders makes the need for more than one medication (polypharmacy) easy to understand as an optimal treatment of complex cases. Thus, the involvement of variant dopamine genes resulting in ADHD and tics may require dopaminergic agonists (methylphenidate or dexedrine) or antagonists (haloperidol, pimozide, risperidone, etc.). The involvement of variant norepinephrine or epinephrine genes resulting in ADHD and behavioral dysregulation, may require $\mathrm{a}_{2}$-adrenergic agonists (eg, clonidine, guanifacine, venlafaxine, and atomoxetine). The involvement of variant serotonergic genes resulting in depression and anxiety disorders may require selective serotonin re-uptake inhibitors (eg, fluoxetine, sertraline, paroxetine, and fluvoxamine). The involvement of other variant genes resulting in $\mathrm{ODD}, \mathrm{CD}$, and other behaviors, may require medications such as valproic acid, molindone, and risperidone (Biederman et al 2007b).

Parents often raise legitimate concerns when their children are placed on any medication, let alone two or more. Explaining ADHD in terms of a complex set of different genes affecting different neurotransmitters often helps to moderate these concerns. To this effect, the utilization of certain specific 
ingredients, which modify the brain reward cascade by targeting serotonergic, opioidergic, GABAergic, catecholaminergic, and acetylcholinergic pathways, can alter behaviors known to be associated with ADHD. Such a polypharmacy approach may include the utilization of a nutraceutical (nutrigenomic) approach targeted at enhancing slow dopamine release in the nucleus accumbens. One available nutraceutical combines the following: select amino acids (5-hydroxytyptophan, dlPhenylalanine, 1-tyrosine, l-glutamine); herbals (Rhodiola rosea, ferulic acid, ginkgo-biloba, ginseng, gotu kola, huperzine A); trace metals (chromium and zinc); macro minerals (calcium, magnesium, manganese); vitamins (ascorbic acid, d-alpha tocopheryl, niacin, pyridoxal-phosphate, B12); and co-factors (biotin, folic acid, dimethylethanoiamine).

In an early study of healthy volunteers, a combination of amino acids and herbals showed positive results (Defrance et al 1977). The researchers observed a significant amplitude enhancement of the P300 component of the cognitive eventrelated brain potentials, as well as improvement in cognitive processing speeds, after the subjects were given the amino acid formula. These improvements in normal volunteers are consistent with the observed facilitation of recovery of individuals with RDS, including substance abuse and ADHD, as well as with dopaminergic involvement in short term memory (Kimberg et al 1997).

\section{Combination therapy: a long-term approach}

The short-term safety and tolerability of psychostimulants has been reasonably well studied, and the risks associated with these compounds in the short term are generally acceptable. However, the amount of long-term effectiveness and safety data related to psychostimulant therapy is relatively small. Data that do exist suggest that long-term treatment with psychostimulants in appropriately diagnosed patients may be associated with salutary effects as well as relatively modest risks. (Kociancic et al 2004). ADHD has an early onset and requires an extended course of treatment. Research is needed to examine the long-term safety of treatment and to investigate whether other forms of treatment could be combined with psychostimulants to lower their doses as well as to reduce other problem behaviors found with ADHD. One important treatment goal is to develop a side-effect free natural product to augment psychostimulants with the ultimate goal of reducing the need for psychostimulants. Core to this therapeutic strategy would be to develop a product with mechanisms of action that would both increase the release of dopamine, and induce long term $\mathrm{D}_{2}$ receptor proliferation.
Such a novel combination therapy would mimic stimulants like methylphenidate, and thus an additive and/or synergistic action should be expected.

In fact, combined therapies might be used to improve overall functioning by targeting symptoms of disorders that often accompany ADHD, such as CD, SUD, and learning disabilities. Moreover, because stimulants also can be abused, and because children with ADHD are at increased risk for substance-seeking behavior, concerns have been raised about the potential for abuse of stimulants by children taking medication or migrating to other drugs of abuse. In this regard, critics argue that many children who do not have true ADHD are medicated as a way to control non-ADHD disruptive behaviors. However, ironically, organizations like CHADD recommend the use of stimulants for schoolaged children, comparing the pills to eyeglasses, braces, and allergy medications (CHADD 2007).

In this regard, the use of methylphenidate and amphetamine, which are the mainstay for the treatment of ADHD, has raised concerns because of their reinforcing effects. That is, the chronic use of these medicines during childhood or adolescence might induce changes in the brain that could facilitate drug abuse in adulthood. This concern was recently addressed by Thanos and colleagues (Thanos et al 2007). They measured the effects of chronic treatment ( 8 months) with oral methylphenidate (1 or $2 \mathrm{mg} / \mathrm{kg}$ ), which was initiated in periadolescent rats (postnatal day 30). Following this treatment, the rats were tested on cocaine self-administration. In addition, at 2 and 8 months of treatment, the investigators measured dopamine $\mathrm{D}_{2}$ receptor $\left(\mathrm{D}_{2} \mathrm{R}\right)$ availability in the striatum using [(11)C]raclopride microPET (muPET) imaging. Animals treated for 8 months with $2 \mathrm{mg} / \mathrm{kg}$ of methylphenidate showed significantly reduced rates of cocaine self-administration at adulthood compared to vehicle-treated rats. $D_{2} R$ availability in the striatum was significantly lower in rats after 2 months of treatment with methylphenidate (1 and $2 \mathrm{mg} / \mathrm{kg}$ ) but significantly higher after 8 months of methylphenidate treatment than in the vehicle-treated rats. In vehicle-treated rats, $D_{2} R$ availability decreased with age, whereas it increased in rats treated with methylphenidate. Because low $\mathrm{D}_{2} \mathrm{R}$ levels in the striatum are associated with a propensity for self-administration of drugs both in laboratory animals and in humans, this effect could underlie the lower rates of cocaine self-administration observed in the rats given 8 months of treatment with methylphenidate. Eight-month treatment with oral methylphenidate beginning in adolescence decreased cocaine self-administration $(1 \mathrm{mg} / \mathrm{kg}$ ) during adulthood which could reflect the increases 
in $\mathrm{D}_{2} \mathrm{R}$ availability observed at this life stage since $\mathrm{D}_{2} \mathrm{R}$ increases are associated with reduced propensity for cocaine self-administration. In contrast, 2-month treatment with methylphenidate started also at adolescence decreased $\mathrm{D}_{2} \mathrm{R}$ availability, which could raise concern that at this life stage, short treatments could possibly increase vulnerability to drug abuse during adulthood. These findings indicate that methylphenidate effects on $\mathrm{D}_{2} \mathrm{R}$ expression in the striatum are sensitive not only to length of treatment but also to the developmental stage at which treatment is given. The authors suggested that future studies evaluating the effects of different lengths of treatment on drug self-administration are required to assess optimal duration of treatment regimes to minimize adverse effects on the propensity for drug selfadministration in humans.

Little is known about the risks and characteristics of ADHD patients who misuse or divert their stimulant medications. As part of a 10-year longitudinal study of youths with ADHD, Wilens et al (2006) evaluated medication diversion or misuse in a young ADHD population. The investigators used structured psychiatric interviews for diagnosis, and a self-report questionnaire regarding medication use in medicated subjects with ADHD compared with controls without ADHD receiving psychotropic medications for non-ADHD treatment. Of 98 subjects receiving psychotropic medications (mean age of $20.8 \pm 5$ years), 55 (56\%) were ADHD subjects and $43(44 \%)$ were controls receiving medications for other purposes. The authors found that $11 \%$ of the ADHD group reported selling their medications compared with no subjects in the control group. An additional $22 \%$ of the ADHD group reported misusing their medications compared with $5 \%$ of the control subjects, and that those with CD or SUD accounted for the misuse and diversion. A minority of subjects reported escalating their doses and concomitant use with alcohol and drugs. Interestingly, the data indicated that the majority of ADHD individuals, particularly those without CD or SUD, used their medications appropriately. The authors' findings also highlighted the need to monitor medication use in ADHD individuals with CD or SUD and to carefully select agents with a low likelihood of diversion or misuse in this group. Based on this report, therefore, it may be helpful for individuals to be tested for candidate genes to determine a predisposition of substance seeking-behavior.

In terms of methamphetamine utilization, there are concerns related to its genotoxic effects. A recent study was conducted to investigate the index of cerebral and peripheral DNA damage in young and adult rats after acute and chronic methylphenidate exposure. The researchers used single cell gel electrophoresis (Comet assay) to measure early DNA damage in hippocampus, striatum, and total blood, as well as a micronucleus test in total blood samples. Their results showed that methylphenidate increased the peripheral index of early DNA damage in young and adult rats, which was more pronounced with chronic treatment and in the striatum compared to the hippocampus. Neither acute nor chronic methylphenidate treatment increased micronucleus frequency in young or in adult rats. Peripheral DNA damage was positively correlated with striatal DNA damage. These results suggest that methylphenidate may induce central and peripheral early DNA damage, but this early damage may be repaired (Andreazza et al 2007).

\section{Alternative treatments}

Because of the concern about the use of medications, many parents seek alternative methods of treatment of ADHD. Most clinicians agree that a combination of medication and behavioral modification is the most effective approach to the treatment of ADHD, even though the medications appear to contribute greater benefits. Children with ADHD may also respond well to adjustments in their education setting, eg, taking advantage of an individualized educational plan. The following are some additional alternatives that are most often used.

\section{EEG biofeedback}

Electroencephalographic (EEG) biofeedback usually utilizes the feedback from a game played on a TV screen to attempt to train the brain to alter the levels of alpha, beta and delta waves. This tactic has the advantage that no drugs are used and appears to be effective in some cases. The disadvantage is that it can be expensive. Satisfactory double blind testing and evaluation of its effectiveness has been very difficult, and the effects may not be long lasting.

\section{Herbal remedies}

Numerous herbal remedies have been used by ADHD patients. Sometimes they seem to be effective, sometimes not, or their effectiveness may be short-lived. Many parents turn to them because they are perceived as "natural". However, to be effective they must contain an active ingredient for which the identity is usually not known. In addition, a wide range of other ingredients may be present that are not necessary or may cause unknown, or worse yet, undesirable side effects. As physicians and pharmacologists, we suggest that using pure medications with known doses, known mechanisms of action and known side effects is always preferable. 


\section{Nutraceuticals}

In contrast to herbal remedies, the composition of other nutraceuticals is more precisely known. They usually consist of amino acids, vitamins, minerals, and other known compounds. Because they are closer to food substances than drugs, they do not have the same rigorous restrictions by the Federal Drug Administration that drugs do and can be purchased over the counter. Because a number of amino acids have direct or indirect effects on the levels of specific neurotransmitters, they have the potential of helping to control some of the symptoms of ADHD. Nutraceuticals have the advantage that double-blind studies (Blum et al 1988) can be easily carried out. It is not unlikely that some combinations of the above compounds, carefully tested in double-blind studies, may play a supporting role in controlling some of the symptoms of ADHD (Blum and Trachtenberg 1988; Blum et al 2000, 2006b; Blum and Payne 1991; Chen et al 2004).

\section{Diets and vitamin supplements}

Hardy et al (2003) compared attentional abilities of two groups of children with ADHD, one group after treatment with Ritalin, and the other after treatment with dietary supplements (a mix of vitamins, minerals, phytonutrients, amino acids, essential fatty acids, phospholipids, and probiotics). Both groups showed significant improvement. These findings support the effectiveness of food supplement treatment in improving attention and self-control in children with ADHD and suggest food supplement treatment of ADHD may be of equal efficacy to Ritalin ${ }^{\circledR}$ treatment.

\section{Dopaminergic and serotonergic releaser combination therapy}

Another treatment for substance-seeking behaviors consists of agonist therapy (not antagonist therapy). This strategy involves administration of stimulant-like medications (eg, monoamine releasers) to alleviate withdrawal symptoms and prevent relapse. A major limitation of this approach is that many candidate medicines possess significant abuse potential because of activation of mesolimbic dopamine neurons in central nervous system reward circuits. Previous data suggest that serotonin neurons can provide regulatory influence over mesolimbic dopamine neurons. Thus, it might be predicted that the balance between dopamine and serotonin transmission is important to consider when developing medications with reduced stimulant side effects. In this article, we have discussed several issues related to the putative mechanisms related to ADHD behaviors. In other recent articles the authors have discussed the potential development of dual dopamine/serotonin releasers for the treatment of substance use disorders (Rothman et al 2007). In this regard, there is evidence supporting the existence of a dual deficit in dopamine and serotonin function during withdrawal from chronic cocaine or alcohol abuse (Rothman et al 2007). Rothman and associates further summarize studies that have tested the hypothesis that serotonin neurons can dampen the effects mediated by mesolimbic dopamine. For example, it has been shown that pharmacological manipulations that increase extracellular serotonin attenuate stimulant effects produced by dopamine release, such as locomotor stimulation and selfadministration behavior. Finally, they discuss their recently published data about PAL-287 (naphthylisopropylamine), a novel non-amphetamine dopamine/serotonin-releasing agent that suppresses cocaine self-administration but lacks positive reinforcing properties (Hiebel et al 2007). Using this concept we have developed the Synaptamine Complex $(\mathrm{SG} 8839)^{\mathrm{TM}}$ and have recently published on its effects (Chen et al 2004). Table 3 provides details about the ingredients of the synaptamine complex, as well as proposed brain targets and behavioral changes.

At the recent XV World Congress of Psychiatric genetics held in New York City, a number of new gene loci presented at the congress included: Nos1 exon 1f-VNTF; NTF3; CNTFR; NTRK2; rs2242447 (noradrenergic transporter gene); HTR1B; beta-tubulin 111; MAP2; ADRA2A; and linkage to chromosome 3, 9, and 16 among others.

\section{Summary}

ADHD is a complex disorder, usually appearing first in childhood, and having multiple causes including genetics as impacted by one's environment. In order to dispel myths about ADHD, it will require examination of the additive effects of multiple genes. Further, and because polygenic inheritance is far more complex than single gene inheritance, an ultimate understanding of the role of any one gene involved in polygenic inheritance will require a summation across many different studies. While the use of psychostimulants has resulted in attenuation of behavioral symptoms in a high percentage of ADHD children, parents have been concerned about potential side effects. In this regard, the extant evidence tends to support the novel concept of an adjunctive polypharmacy approach for the prevention and treatment of ADHD rather than single neurochemical and/or neurogenetic targets (eg, $\mathrm{D}_{1}-\mathrm{D}_{5}, \mathrm{DAT}_{1}, \mathrm{DBH}, \mathrm{COMT}, 5 \mathrm{HT} 1 \mathrm{~B}, \mathrm{NR} 4 \mathrm{~A} 2$, SLC1A3, BDNF, as well as loci at 4q13.2, 5q33.3, 11q22 and $17 \mathrm{p} 11$ [see above]).

Hopefully, because of advances in molecular pharmacology, nutrition, and molecular genetics, the legacy 


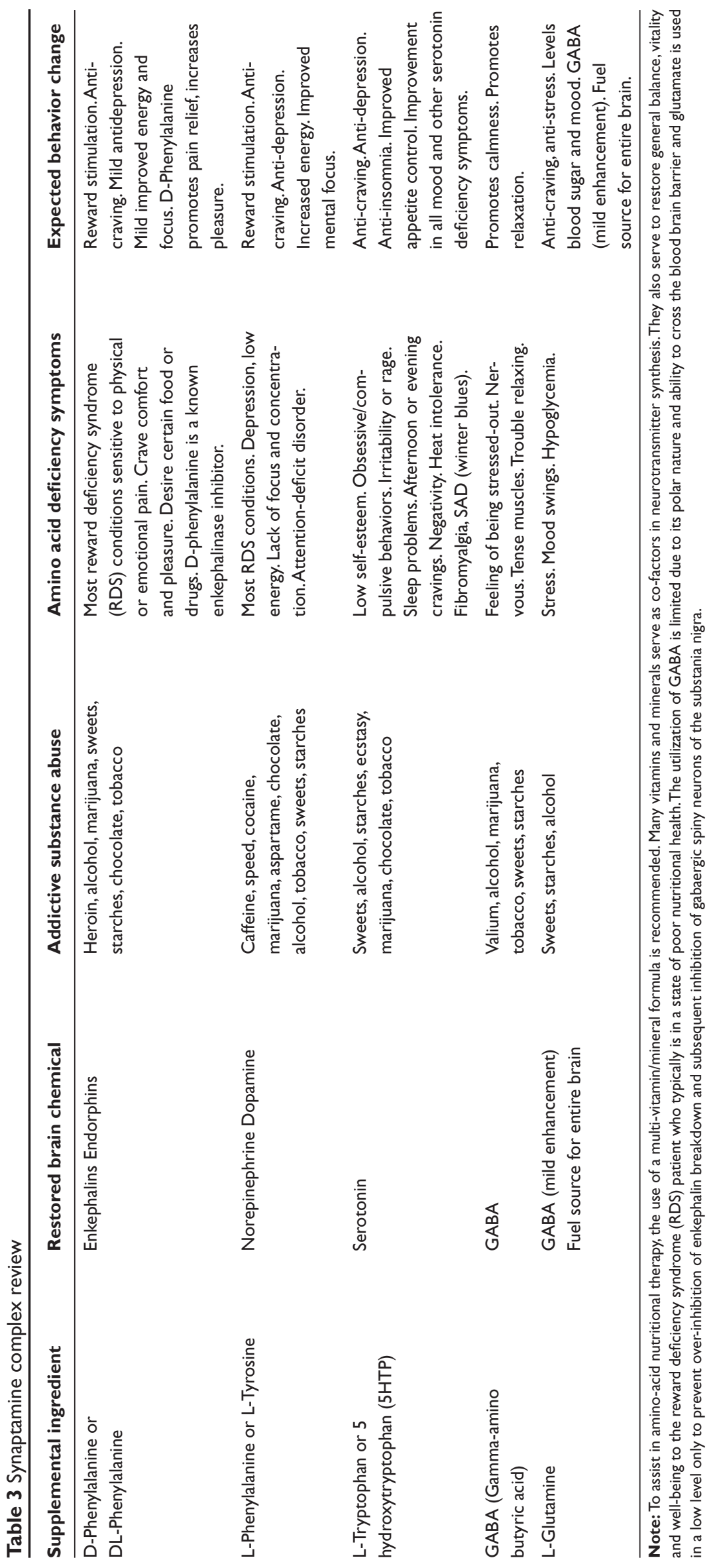

Neuropsychiatric Disease and Treatment 2008:4(5) 
of RDS and subtype ADHD behavior will be reduced. In order to advance these goals, we recommend diagnosis of ADHD using the specific DNA polymorphic analysis coupled with electrophysiological and computerized testing, especially in young children. In this regard, (Larsson et al 2006) suggested that the finding of persistent cross-subtype (ie, combined) and persistent subtype-specific genetic influences (ie, primarily hyperactive-impulsive and inattentive disorders) are in line with a genetic basis for the DSM-IV classification of ADHD subtypes (Table 1). Finally, considerable evidence suggests that, rather than a single pharmaceutical treatment approach, DNA-based personalized nutraceutical therapies should be considered.

\section{Abbreviations}

5HT: 5-hydroxytryptamine (serotonin); AACP: American Academy of Child and Adolescent Psychiatry ADD: attention deficit disorder; DHD: attention deficit hyperactivity disorder; ADHD-C: attention deficit hyperactivity disorder, combined type; ADHD-H: attention deficit hyperactivity disorder hyperactive, impulsive type; ADHD-I: attention deficit hyperactivity disorder, inattentive type; APA: American Psychiatric Association; BDNF: Brain-derived neurotrophic factor; CAx: cluster cells in the hippocampus; CD: conduct disorder; CGI: Clinical Global Impression Scale; CHADD: children and adults with ADHD; COMT: catechol-O-methyltransferase; CSF: cerebrospinal fluid; $\mathrm{D}_{\mathrm{x}}$ : dopamine genes $\left(\mathrm{D}_{1}, \mathrm{D}_{2}\right.$, etc.); DAT: dopamine transporter; DBH: dopamine beta-hydroxylase; DNA: deoxyribonucleic acid; $\mathrm{DRD}_{\mathrm{x}}$ : dopamine receptor genes $\left(\mathrm{DRD}_{1}, \mathrm{DRD}_{2}\right.$, etc.); DSM-IV: Diagnostic and Statistical Manual (Version IV); EEG: electroencephalography; GABA: gamma-amino butyric acid LDX: lisdexamfetamine dimesylate; NIAAA: National Institute on Alcohol Abuse and Alcoholism; OCD: obsessive compulsive disorder; ODD: oppositional defiant disorder; PERMP: Permanent Product Measure of Performance; PET: positron emission tomography; RDS: reward deficiency syndrome; SKAMP: Swanson, Kotkin, Agler, M-Flynn, and Pelham Rating Scale; SNP: single nucleotide polymorphism; SPECT: single photon emission computed tomography; SUD: substance use disorder; TDO: tryptophan 2,3-dioxygenase; T.O.V.A.: Test of Variables of Attention

\section{Acknowledgments}

The writing of this review was supported in part by funds from the US Department of Health and Human Services, NIAAA (R01-AA07112 and K05-AA00219) and the Medical Research Service of the US Department of Veterans Affairs to Marlene Oscar-Berman. The authors want to thank PATH Medical and Research Foundation and LifeGen, Inc. for their generous financial support.

\section{Disclosures}

Kenneth Blum, Bernard Downs, Roger Waite, and Lonna Williams own stock in, and are officers of, LifeGen Inc., a company involved in DNA-directed nutrition for ADHD.

\section{References}

Andreazza AC, Frey BN, Valvassori SS, et al. 2007. DNA damage in rats after treatment with methylphenidate. Prog Neuropsychopharmacol Biol Psychiatry, 31:1282-8.

APA. 1994. Diagnostic and statistical manual of mental disorders (DSM-IV). Washington, D.C: American Psychiatric Association.

APA. 2000. Diagnostic and statistical manual of the American Psychiatric Association. Washington, DC: American Psychiatric Association.

Arcos-Burgos M, Castellanos FX, Pineda D, et al. 2004. Attention-deficit/ hyperactivity disorder in a population isolate: linkage to loci at 4q13.2, 5q33.3, 11q22, and 17p11. Am J Hum Genet, 75:998-1014.

Asherson P, Kuntsi J, Taylor E. 2005. Unravelling the complexity of attention-deficit hyperactivity disorder: a behavioural genomic approach. Br J Psychiatry, 187:103-5.

August GJ, Stewart MA. 1983. Familial subtypes of childhood hyperactivity. J Nerv Ment Dis, 171:362-8.

Biederman J, Boellner SW, Childress A, et al. 2007a. Lisdexamfetamine Dimesylate and mixed amphetamine salts extended-release in children with ADHD: A double-blind, placebo-controlled, crossover analog classroom study. Biol Psychiatry, 62:970-6.

Biederman J, Faraone SV, Keenan K, et al. 1992. Further evidence for family-genetic risk factors in attention deficit hyperactivity disorder. Patterns of comorbidity in probands and relatives psychiatrically and pediatrically referred samples. Arch Gen Psychiatry, 49:728-38.

Biederman J, Gao H, Rogers AK, Spencer TJ. 2006. Comparison of parent and teacher reports of attention-deficit/hyperactivity disorder symptoms from two placebo-controlled studies of atomoxetine in children. Biol Psychiatry, 60:1106-10.

Biederman J, Spencer TJ, Newcorn JH, et al. 2007b. Effect of comorbid symptoms of oppositional defiant disorder on responses to atomoxetine in children with ADHD: a meta-analysis of controlled clinical trial data. Psychopharmacology (Berl), 190:31-41.

Blum K, Braverman ER, Holder JM, Lubar JF, et al. 2000. Reward deficiency syndrome: a biogenetic model for the diagnosis and treatment of impulsive, addictive, and compulsive behaviors. J Psychoactive Drugs, 32(Suppl i-iv)1-112.

Blum K, Cull JG, Braverman ER, Comings DE. 1996a. Reward deficiency syndrome. Am Sci, 84:132.

Blum K, Kozlowski GP. 1990a. Ethanol and neuromodulator influences. A cascade model of reward. In: Ollat H, Parvez S, Parvez H (eds). Alcohol and behaviour: Basic and clinical aspects. Utrecht, Netherlands: VSP.

Blum K, Kozlowski GP. 1990b. Ethanol and Neuromodulator influences. A cascade model of reward. In: Ollat H, Parvez S, Parvez H (eds). Alcohol and Behaviour: Basic and Clinical Aspects Progress in Alcohol Research. Utrecht, Netherlands: VSP.

Blum K, Meshkin B, Downs BW. 2006a. DNA based customized nutraceutical "gene therapy" utilizing a genoscore: a hypothesized paradigm shift of a novel approach to the diagnosis, stratification, prognosis and treatment of inflammatory processes in the human. Med Hypotheses, 66:1008-18.

Blum K, Meshkin B, Downs BW. 2006b. DNA based customized nutraceutical "gene therapy" utilizing a genoscore: a hypothesized paradigm shift of a novel approach to the diagnosis, stratification, prognosis and treatment of inflammatory processes in the human. Med Hypotheses, 66:1008-18. 
Blum K, Noble EP, Sheridan PJ, et al. 1990. Allelic association of human dopamine D2 receptor gene in alcoholism. JAMA, 263:2055-60.

Blum K, Payne JE. 1991. Alcohol and the addictive brain: new hope for alcoholics from biogenetic research. New York: Free Press. xiv, $320 \mathrm{p}$.

Blum K, Sheridan PJ, Wood RC, et al. 1996b. The D2 dopamine receptor gene as a determinant of reward deficiency syndrome. $J R$ Soc Med, 89:396-400.

Blum K, Trachtenberg MC. 1988. Neurogenetic deficits caused by alcoholism: restoration by SAAVE, a neuronutrient intervention adjunct. J Psychoactive Drugs, 20:297-313.

Blum K, Trachtenberg MC, Elliott CE, et al. 1988. Enkephalinase inhibition and precursor amino acid loading improves inpatient treatment of alcohol and polydrug abusers: double-blind placebo-controlled study of the nutritional adjunct SAAVE. Alcohol, 5:481-93.

Bowirrat A, Oscar-Berman M. 2005. Relationship between dopaminergic neurotransmission, alcoholism, and Reward Deficiency Syndrome. $A m$ J Med Genet B Neuropsychiatr Genet, 132:29-37.

Braverman ER, Chen TJ, Schoolfield J, et al. 2006. Delayed P300 latency correlates with abnormal Test of Variables of Attention (TOVA) in adults and predicts early cognitive decline in a clinical setting. $A d v$ Ther, 23:582-600.

Brookes $\mathrm{K}, \mathrm{Xu} \mathrm{X}$, Chen W, et al. 2006. The analysis of 51 genes in DSM-IV combined type attention deficit hyperactivity disorder: association signals in DRD4, DAT1 and 16 other genes. Mol Psychiatry, 11:934-53.

Cantwell DP. 1972. Psychiatric illness in the families of hyperactive children. Arch Gen Psychiatry, 27:414-7.

Cantwell DP. 1976. Genetic factors in the hyperkinetic syndrome. $J$ Am Acad Child Psychiatry, 15:214-23.

Castellanos FX, Lau E, Tayebi N, et al. 1998. Lack of an association between a dopamine-4 receptor polymorphism and attention-deficit/ hyperactivity disorder: genetic and brain morphometric analyses. Mol Psychiatry, 3:431-4

CHADD. 2007. CHADD's educators manual. Landover, MD: CHADD.

Chen TJ, Blum K, Payte JT, et al. 2004. Narcotic antagonists in drug dependence: pilot study showing enhancement of compliance with SYN-10, amino-acid precursors and enkephalinase inhibition therapy Med Hypotheses, 63:538-48.

Cloninger CR, Svrakic DM, Przybeck TR. 1993. A psychobiological model of temperament and character. Arch Gen Psychiatry, 50:975-90.

Comings DE. 2001. Clinical and molecular genetics of ADHD and Tourette syndrome. Two related polygenic disorders. Ann N Y Acad Sci, 931:50-83.

Comings DE, Chen TJ, Blum K, et al. 2005. Neurogenetic interactions and aberrant behavioral co-morbidity of attention deficit hyperactivity disorder (ADHD): dispelling myths. Theor Biol Med Model, 2:50doi:10.1186/1742-4682-2-50

Comings DE, Comings BG, Muhleman D, et al. 1991. The dopamine D2 receptor locus as a modifying gene in neuropsychiatric disorders. JAMA, 266:1793-800.

Comings DE, Gade-Andavolu R, Gonzalez N, et al. 2000. Multivariate analysis of associations of 42 genes in ADHD, ODD and conduct disorder. Clin Genet, 58:31-40.

Comings DE, Wu S, Chiu C, et al. 1996. Polygenic inheritance of Tourette syndrome, stuttering, attention deficit hyperactivity, conduct, and oppositional defiant disorder: the additive and subtractive effect of the three dopaminergic genes - DRD2, D beta H, and DAT1. Am J Med Genet, 67:264-88.

Conners CK. 2006. CRS-R (Conners' Rating Scales-Revised). Minneapolis, $\mathrm{MN}$ : Pearson Assessment Group.

Cook EH, Jr., Stein MA, Krasowski MD, et al. 1995. Association of attention-deficit disorder and the dopamine transporter gene. Am J Hum Genet, 56:993-8.

Defrance JF, Hymel C, Trachtenberg MC, et al. 1977. Enhancement of attentional processing by Kantroll in healthy humans: A pilot study. Clin Electroencephalography, 28:68-75.
Dyr W, McBride WJ, Lumeng L, et al. 1993. Effects of D1 and D2 dopamine receptor agents on ethanol consumption in the high-alcohol-drinking (HAD) line of rats. Alcohol, 10:207-12.

Faraone SV. 2003. Report from the 4th international meeting of the attention deficit hyperactivity disorder molecular genetics network. Am J Med Genet B Neuropsychiatr Genet, 121:55-9.

Faraone SV, Biederman J, Keenan K, et al. 1991. A family-genetic study of girls with DSM-III attention deficit disorder. Am J Psychiatry, 148:112-7.

Farde L, Gustavsson JP, Jonsson E. 1997. D2 dopamine receptors and personality traits. Nature, 385(6617):590.

Gadow KD, Nolan EE, Sverd J. 1992. Methylphenidate in hyperactive boys with comorbid tic disorder: II. Short-term behavioral effects in school settings. J Am Acad Child Adolesc Psychiatry, 31:462-71.

Gill M, Daly G, Heron S, et al. 1997. Confirmation of association between attention deficit hyperactivity disorder and a dopamine transporter polymorphism. Mol Psychiatry, 2:311-3.

Heiser P, Friedel S, Dempfle A, et al. 2004. Molecular genetic aspects of attention-deficit/hyperactivity disorder. Neurosci Biobehav Rev, 28:625-41.

Hiebel AC, Lee YS, Bilsky E, et al. 2007. Probes for narcotic receptor mediated phenomena. 34. synthesis and structure-activity relationships of a potent mu-agonist delta-antagonist and an exceedingly potent antinociceptive in the enantiomeric $\mathrm{C} 9$-substituted 5-(3-hydroxyphenyl)-N-phenylethylmorphan series. J Med Chem, 50:65-75.

Howell DC, Huessy HR, Hassuk B. 1985. Fifteen-year follow-up of a behavioral history of attention deficit disorder. Pediatrics, 76:185-90.

Imperato A, Di Chiara G. 1988. Effects of locally applied D-1 and D-2 receptor agonists and antagonists studied with brain dialysis. Eur $J$ Pharmacol, 156:385-93.

Inkster B, Muglia P, Jain U, et al. 2004. Linkage disequilibrium analysis of the dopamine beta-hydroxylase gene in persistent attention deficit hyperactivity disorder. Psychiatr Genet, 14:117-20.

Jönsson E, Sedvall G, Brene S, et al. 1996. Dopamine-related genes and their relationships to monoamine metabolites in CSF. Biol Psychiatry, 40:1032-43.

Kent L, Green E, Hawi Z, et al. 2005. Association of the paternally transmitted copy of common Valine allele of the Val66Met polymorphism of the brain-derived neurotrophic factor (BDNF) gene with susceptibility to ADHD. Mol Psychiatry, 10:939-43.

Kimberg DY, D'Esposito M, Farah MJ. 1997. Effects of bromocriptine on human subjects depend on working memory capacity. Neuroreport, 8:3581-5.

Kirley A, Lowe N, Hawi Z, et al. 2003. Association of the 480 bp DAT1 allele with methylphenidate response in a sample of Irish children with ADHD. Am J Med Genet B Neuropsychiatr Genet, 121:50-4.

Koob GF, Bloom FE. 1988. Cellular and molecular mechanisms of drug dependence. Science, 242(4879):715-723.

Krause J, Dresel SH, Krause KH, et al. 2003. The dopamine transporter and neuroimaging in attention deficit hyperactivity disorder. Neurosci Biobehav Rev, 27:605-13.

Krause J, Krause KH, Dresel SH, et al. 2006. ADHD in adolescence and adulthood, with a special focus on the dopamine transporter and nicotine. Dialogues Clin Neurosci, 8:29-36.

Krause J, la Fougere C, Krause KH, et al. 2005. Influence of striatal dopamine transporter availability on the response to methylphenidate in adult patients with ADHD. Europ Arch Psychiatry Clin Neurosci, $255: 428-31$

la Fougere C, Krause J, Krause KH, et al. 2006. Value of 99mTc-TRODAT1 SPECT to predict clinical response to methylphenidate treatment in adults with attention deficit hyperactivity disorder Nuclear Med Commun, 27:733-7.

LaHoste GJ, Swanson JM, Wigal SB, et al. 1996. Dopamine D4 receptor gene polymorphism is associated with attention deficit hyperactivity disorder. Mol Psychiatry, 1:121-4. 
Larsson H, Lichtenstein P, Larsson JO. 2006. Genetic contributions to the development of ADHD subtypes from childhood to adolescence. $J$ Am Acad Child Adolesc Psychiatry, 45:973-81.

Laurin N, Misener VL, Crosbie J, et al. 2005. Association of the calcyon gene (DRD1IP) with attention deficit/hyperactivity disorder. Mol Psychiatry, 10:1117-25.

Le Moal M, Simon H. 1991. Mesocorticolimbic dopaminergic network: functional and regulatory roles. Physiol Rev, 71:155-234.

Lee HJ, Lee HS, Kim YK, et al. 2003. D2 and D4 dopamine receptor gene polymorphisms and personality traits in a young Korean population. Am J Med Genet B Neuropsychiatr Genet, 121:44-9.

Li D, Sham PC, Owen MJ, He L. 2006. Meta-analysis shows significant association between dopamine system genes and attention deficit hyperactivity disorder (ADHD). Hum Mol Genet, 15:2276-84.

Lou HC, Andresen J, Steinberg B, et al. 1998. The striatum in a putative cerebral network activated by verbal awareness in normals and in ADHD children. Eur J Neurol, 5:67-74.

Lubar JF. 1991. Discourse on the development of EEG diagnostics and biofeedback for attention-deficit/hyperactivity disorders. Biofeedback Self Regul, 16:201-25.

Madras BK, Miller GM, Fischman AJ. 2005. The dopamine transporter and attention-deficit/hyperactivity disorder. Biol Psychiatry, 57:1397-409.

Malison RT, McDougle CJ, van Dyck CH, et al. 1995. [123I]beta-CIT SPECT imaging of striatal dopamine transporter binding in Tourette's disorder. Am J Psychiatry, 152:1359-61.

McBride WJ, Chernet E, Dyr W, et al. 1993. Densities of dopamine D2 receptors are reduced in CNS regions of alcohol-preferring P rats. Alcohol, 10:387-90.

McBride WJ, Guan XM, Chernet E, Lumeng L, Li TK. 1994. Regional serotonin1A receptors in the CNS of alcohol-preferring and -nonpreferring rats. Pharmacol Biochem Behav, 49:7-12.

Mill J, Caspi A, Williams BS, et al. 2006. Prediction of heterogeneity in intelligence and adult prognosis by genetic polymorphisms in the dopamine system among children with attention-deficit/hyperactivity disorder: evidence from 2 birth cohorts. Arch Gen Psychiatry, 63:462-9.

Miller D, Blum K. 2008. Overload: Attention deficit disorder and the addictive brain. Salt Lake City, Utah: Woodland Publishing Company.

Noble EP. 2003. D2 dopamine receptor gene in psychiatric and neurologic disorders and its phenotypes. Am J Med Genet B Neuropsychiatr Genet, 116:103-25.

Noble EP, Berman SM, Ozkaragoz TZ, Ritchie T. 1994. Prolonged P300 latency in children with the D2 dopamine receptor A1 allele. Am J Hum Genet, 54:658-68.

Noble EP, Gottschalk LA, Fallon JH, et al. 1997. D2 dopamine receptor polymorphism and brain regional glucose metabolism. Am J Med Genet, 74:162-6.

Olds J. 1956. A preliminary mapping of electrical reinforcing effects in the rat brain. J Comp Physiol Psychol, 49:281-5.

Ollat H, Parvez S, Parvez H. 1990. Alcohol and behaviour: basic and clinical aspects. Progress in alcohol research. Utrecht, Netherlands: VSP. p vi, 285 p.

Ortiz J, Fitzgerald LW, Charlton M, et al. 1995. Biochemical actions of chronic ethanol exposure in the mesolimbic dopamine system. Synapse, 21:289-98.

Pauls DL, Leckman JF. 1986. The inheritance of Gilles de la Tourette's syndrome and associated behaviors. Evidence for autosomal dominant transmission. N Engl J Med, 315:993-7.

Perwien AR, Kratochvil CJ, Faries DE, et al. 2006. Atomoxetine treatment in children and adolescents with attention-deficit hyperactivity disorder: what are the long-term health-related quality-of-life outcomes? J Child Adolesc Psychopharmacol, 16:713-24.

Pohjalainen T, Rinne JO, Nagren K, et al. 1998. The A1 allele of the human D2 dopamine receptor gene predicts low D2 receptor availability in healthy volunteers. Mol Psychiatry, 3:256-60.
Rothman RB, Blough BE, Baumann MH. 2007. Dual dopamine/serotonin releasers as potential medications for stimulant and alcohol addictions. AAPS J, 9:E1-10.

Russell VA, Lamm MC, Taljaard JJ. 1988. Effect of ethanol on $[3 \mathrm{H}]$ dopamine release in rat nucleus accumbens and striatal slices. Neurochem Res, 13:487-92.

Safer DJ. 1973. "A familial factor in minimal brain dysfunction. Behav Genet, 3:175-86.

Seeman P, Madras BK. 1998. Anti-hyperactivity medication: methylphenidate and amphetamine. Mol Psychiatry, 3:386-96.

Shaw P, Gornick M, Lerch J, et al. 2007. Polymorphisms of the dopamine d4 receptor, clinical outcome, and cortical structure in attention-deficit/ hyperactivity disorder. Arch Gen Psychiatry, 64:921-31.

Shaywitz BA, Yager RD, Klopper JH. 1976. Selective brain dopamine depletion in developing rats: an experimental model of minimal brain dysfunction. Science, 191(4224):305-8.

Smith KM, Bauer L, Fischer M, et al. 2005. Identification and characterization of human NR4A2 polymorphisms in attention deficit hyperactivity disorder. Am J Med Genet B Neuropsychiatr Genet, 133:57-63.

Spencer T, Biederman J, Heiligenstein J, et al. 2001. An open-label, doseranging study of atomoxetine in children with attention deficit hyperactivity disorder. J Child Adolesc Psychopharmacol, 11:251-65.

Spencer TJ, Faraone SV, Michelson D, et al. 2006. Atomoxetine and adult attention-deficit/hyperactivity disorder: the effects of comorbidity. $J$ Clin Psychiatry, 67:415-20.

Stein L, Belluzzi J. 1986. Second messengers, natural rewards, and drugs of abuse. Clin Neuropharmacol, 9(Suppl 4):205-7.

Swanson JM, Kinsbourne M, Nigg J, et al. 2007. Etiologic subtypes of attention-deficit/hyperactivity disorder: brain imaging, molecular genetic and environmental factors and the dopamine hypothesis. Neuropsychol Rev, 17:39-59.

Thanos PK, Michaelides M, Benveniste H, et al. 2007. Effects of chronic oral methylphenidate on cocaine self-administration and striatal dopamine D2 receptors in rodents. Pharmacol Biochem Behav, 87:426-33.

TOVA. 2006. T.O.V.A. (Test of Variables of Attention). Los Alamitos, CA: The TOVA Company.

Turic D, Langley K, Williams H, et al. 2005a. A family based study implicates solute carrier family 1-member 3 (SLC1A3) gene in attentiondeficit/hyperactivity disorder. Biol Psychiatry, 57:1461-6.

Turic D, Williams H, Langley K, et al. 2005b. A family based study of catechol-O-methyltransferase (COMT) and attention deficit hyperactivity disorder (ADHD). Am J Med Genet B Neuropsychiatr Genet, 133:64-7.

Volkow ND, Ding YS, Fowler JS, et al. 1995. Is methylphenidate like cocaine? Studies on their pharmacokinetics and distribution in the human brain. Arch Gen Psychiatry, 52:456-63.

Volkow ND, Wang GJ, Newcorn J, et al. 2007. Depressed dopamine activity in caudate and preliminary evidence of limbic involvement in adults with attention-deficit/hyperactivity disorder. Arch Gen Psychiatry, 64:932-40.

Waldman ID, Mohr JH, Abramowitz A, et al. 1998. The relation between childhood antisocial behavior and the dopamine transporter gene (DAT1). Mediation via hyperactivity-impulsivity. Am J Med Gen B Neuropsychiatr Genet, 81:451-556.

Wallis D, Russell HF, Muenke M. 2008. Genetics of attention deficit/hyperactivity disorder. J Pediatr Psychol, Jun 3 [Epub ahead of print].

Welner Z, Welner A, Stewart M, et al. 1977. A controlled study of siblings of hyperactive children. J Nerv Ment Dis, 165:110-7.

Wilens TE, Gignac M, Swezey A, et al. 2006. Characteristics of adolescents and young adults with ADHD who divert or misuse their prescribed medications. J Am Acad Child Adolesc Psychiatry, 45:408-14.

Willerman L. 1973. Activity level and hyperactivity in twins. Child Dev, 44:288-93.

Winsberg BG, Comings DE. 1999. Association of the dopamine transporter gene (DAT1) with poor methylphenidate response. J Am Acad Child Adolesc Psychiatry, 38:1474-7. 
Wise RA, Bozarth MA. 1984. Brain reward circuitry: four circuit elements "wired" in apparent series. Brain Res Bull, 12:203-8.

Wolf SS, Jones DW, Knable MB, et al. 1996. Tourette syndrome: prediction of phenotypic variation in monozygotic twins by caudate nucleus D2 receptor binding. Science, 273(5279):1225-7.

Wolraich ML, Hannah JN, Baumgaertel A, Feurer ID. 1998. Examination of DSM-IV criteria for attention deficit/hyperactivity disorder in a county-wide sample. J Dev Behav Pediatr, 19:162-8.
Zametkin AJ, Nordahl TE, Gross M, et al. 1990. Cerebral glucose metabolism in adults with hyperactivity of childhood onset. $N$ Engl $J$ Med, 323:1361-6.

Zhou FC, Bledsoe S, Lumeng L, Li TK. 1991. Immunostained serotonergic fibers are decreased in selected brain regions of alcohol-preferring rats. Alcohol, 8:425-31. 
